\title{
Zinc stress induces copper depletion in Acinetobacter baumannii
}

\author{
Karl A. Hassan', Victoria G. Pederick², Liam D. H. Elbourne', Ian T. Paulsen ${ }^{1}$, James C. Paton², \\ Christopher A. McDevitt ${ }^{*}$ and Bart A. Eijkelkamp ${ }^{2^{*}}$
}

\begin{abstract}
Background: The first row transition metal ions zinc and copper are essential to the survival of many organisms, although in excess these ions are associated with significant toxicity. Here, we examined the impact of zinc and copper stress on Acinetobacter baumannii, a common opportunistic pathogen.

Results: We show that extracellular zinc stress induces a copper-specific depletion phenotype in A. baumannii ATCC 17978. Supplementation with copper not only fails to rescue this phenotype, but further exacerbates the copper depletion. Extensive analysis of the A. baumannii ATCC 17978 genome identified 13 putative zinc/copper resistance efflux pumps. Transcriptional analyses show that four of these transporters are responsive to zinc stress, five to copper stress and seven to the combination of zinc and copper stress, thereby revealing a likely foundation for the zinc-induced copper starvation in A. baumannii. In addition, we show that zinc and copper play crucial roles in management of oxidative stress and the membrane composition of A. baumannii. Further, we reveal that zinc and copper play distinct roles in macrophage-mediated killing of this pathogen.
\end{abstract}

Conclusions: Collectively, this study supports the targeting of metal ion homeostatic mechanisms as an effective antimicrobial strategy against multi-drug resistant bacterial pathogens.

Keywords: Acinetobacter, Zinc, Copper, Transporter, Oxidative stress, Fatty acids, Macrophages, Membrane

\section{Background}

Acinetobacter baumannii is a Gram-negative opportunistic human bacterial pathogen that is ubiquitous in hospital environments $[1,2]$. Although genetically distinct from their nosocomial counterparts, community-acquired $A$. baumannii isolates are increasingly being recognized as serious threats to human health [3-5]. The A. baumannii pan-genome features a broad arsenal of antibiotic resistance determinants [6] and its genomic plasticity has also led to major differences in genes that play a role in persistence and virulence between strains $[2,4,7-11]$. Thus, the success of this human pathogen can, at least in part, be attributed to the ability of $A$. baumannii to readily incorporate foreign genetic material.

Although the mechanisms involved in the acquisition of essential transition metals ions, such as zinc ( $\mathrm{Zn})$ and

\footnotetext{
* Correspondence: christopher.mcdevitt@adelaide.edu.au; bart.eijkelkamp@adelaide.edu.au

${ }^{2}$ Research Centre for Infectious Diseases, School of Biological Sciences, University of Adelaide, Adelaide, SA, Australia

Full list of author information is available at the end of the article
}

iron (Fe), have been studied in detail in A. baumannii [12-19], how this organism responds to extracellular metal ion stress and intoxication remains poorly understood. In A. baumannii the first row transition metal ions $\mathrm{Zn}$ and copper $(\mathrm{Cu})$ have critical roles in numerous cellular processes and are essential for viability $[12,13$, 20]. However, the ability of $\mathrm{Zn}$ and $\mathrm{Cu}$ to form highly stable complexes with proteins necessitates their cellular abundance be tightly regulated to prevent intoxication that would lead to the inappropriate and highly detrimental binding of these ions to non-cognate metal binding sites, such as the Fe-S clusters of metalloproteins [21-23]. The molecular basis of Zn toxicity is multifactorial with $\mathrm{Zn}$ intoxication leading to perturbed transition metal ion homeostasis, impairment of oxidative stress response mechanisms [24, 25] and disruption of central carbon metabolism [26]. In the Gram-positive human pathogen Streptococcus pneumoniae extracellular Zn has been shown to compete for binding to the manganese $(\mathrm{Mn})$-recruiting lipoprotein PsaA, resulting in inhibition of $\mathrm{Mn}$ acquisition [25, 27]. As $\mathrm{Mn}$ is the 
primary co-factor for the sole known superoxide dismutase in S. pneumoniae, $\mathrm{Zn}$-stressed, and consequently Mn-starved, S. pneumoniae cells are hyper-susceptible to oxidative stress $[27,28]$. By contrast with $\mathrm{Zn}, \mathrm{Cu}$ toxicity has typically been associated with its redox activity and potential to generate reactive oxygen species. However, in isolation $\mathrm{Cu}$ intoxication has been shown to be insufficient to induce oxidative stress [22]. Despite this, at the host-pathogen interface, $\mathrm{Cu}$ in combination with other factors, such as hydrogen peroxide, can contribute to antimicrobial oxidative stress [29-31]. The human innate immune system has also been shown to exploit the antimicrobial activity of metal ions with recent studies showing the importance of $\mathrm{Zn}$ and $\mathrm{Cu}$ mobilisation in tissues and phagocytic cells with respect to clearance of Salmonella and Streptococcus pyogenes infections [32-35].

Bacterial evasion of metal toxicity is facilitated by a number of distinct mechanisms with the major theme being that of metal efflux [36, 37]. For $\mathrm{Cu}$, the P-type ATPase efflux systems, such as CopA from Escherichia coli [38], are highly efficient in exporting the metal from the cytoplasm. $\mathrm{Cu}$ resistance is also achieved through the action of the CopB outer membrane protein (OMP), and periplasmic multi-copperoxidases, such as CopA of Pseudomonas syringae and CueO of E. coli $[39,40]$. In Gram-negative bacteria, $\mathrm{Cu}$ as well as $\mathrm{Zn}$ can be exported by the Heavy Metal Efflux (HME) family of transporters, which are a subclass of the tripartite Resistance-Nodulation cell Division (RND) family of efflux pumps. These are large multimembrane-spanning protein complexes, comprised of inner membrane proteins, periplasmic membrane fusion proteins and OMPs $[41,42]$. Together these complexes allow for the export of metal ions across the outer membrane and into the extracellular milieu, thereby preventing intracellular toxicity. Both $\mathrm{Zn}$ and $\mathrm{Cu}$ are known substrates of the HME efflux systems, with CusCFBA from E. coli being a well-characterised example of a $\mathrm{Cu}$-exporting HME transporter [43]. Efflux of metal ions is also achieved via the cation diffusion facilitator (CDF) family of transporters, which includes members capable of exporting $\mathrm{Zn}$ and/or $\mathrm{Cu}$. The most well characterised CDF is YiiP from E. coli, with a high-resolution crystal structure of the protein providing significant insight into the metal ion translocation pathway of these transporters [44]. Finally, although predominantly known for their role in magnesium transport, various members of the CorA family have also been shown to export $\mathrm{Zn}$, with these proteins classified as ZntB-like proteins [45, 46]. Despite these systems being well characterised in a range of bacterial species, the mechanisms by which $A$. baumannii responds to metal toxicity, particularly that mediated by zinc, have not been elucidated.
Here, we investigated the individual and combined impact of $\mathrm{Zn}$ and $\mathrm{Cu}$ stress on $\mathrm{A}$. baumannii. By combining phenotypic studies with extensive genome and transcriptional analyses, we identified genes that play a role in resistance to $\mathrm{Zn}$ and $\mathrm{Cu}$ intoxication and show how metal stress impacts $A$. baumannii physiology.

\section{Methods}

Bacterial strains, chemicals, media and growth

The Acinetobacter strains used in this study have been described previously [4]. All chemicals were purchased from Sigma Aldrich unless otherwise indicated. A. baumannii strains were routinely grown in Luria Bertani broth (LB), containing 1\% tryptone (BD Bacto), $0.5 \%$ yeast extract (BD Bacto) and 1\% sodium chloride. For routine overnight culturing of A. baumannii strains, a single colony from LB agar was used to inoculate $5 \mathrm{~mL}$ of LB medium. Overnight cultures were diluted to an optical density at $600 \mathrm{~nm}\left(\mathrm{OD}_{600}\right)$ of 0.01 in either $200 \mu \mathrm{L}$ for growth assays or $20 \mathrm{~mL}$ for all other analyses. For growth assays, cultures in LB media were incubated at $37{ }^{\circ} \mathrm{C}$ with shaking in a FLUOStar Omega Spectrophotometer (BMG Labtech), with the $\mathrm{OD}_{600}$ values presented (Fig. 1 and Additional file 1). To assess the impact of $\mathrm{ZnSO}_{4}$ and/or $\mathrm{CuSO}_{4}$ stress, paraquat, hydrogen peroxide or arachidonic acid on $A$. baumannii fitness, $\mathrm{EC}_{50}$ values were calculated from the $\mathrm{OD}_{600}$ measurements using Graphpad Prism 6.0, and then compared between treated and untreated cultures (Figs. 4, 5a, d and 6e). The $20 \mathrm{~mL}$ cultures used for all other analyses were incubated at $37{ }^{\circ} \mathrm{C}$ in an Innova $40 \mathrm{R}$ shaking incubator (Eppendorf) at $230 \mathrm{rpm}$ until they reached mid log-phase $\left(\mathrm{OD}_{600}=0.7\right)$.

\section{Cellular metal ion content analysis}

Untreated and metal-stressed bacteria (LB supplemented with $400 \mu \mathrm{M} \mathrm{ZnSO}_{4}, 400 \mu \mathrm{M} \mathrm{CuSO}_{4}$, or $400 \mu \mathrm{M} \mathrm{ZnSO}_{4}$ and $400 \mu \mathrm{M} \mathrm{CuSO}_{4}$ ) were harvested at mid log-phase and washed, by resuspension and centrifugation at $7000 \times g$ for 8 mins, three times with phosphate-buffered saline (PBS) containing $5 \mathrm{mM}$ ethylenediaminetetraacetic acid (EDTA), and then 6 times with PBS as described previously [47-50]. Bacterial pellets were desiccated at $95{ }^{\circ} \mathrm{C}$ overnight. The dry cell weight was measured and the pellets resuspended in $35 \% \mathrm{HNO}_{3}$ and boiled at $95{ }^{\circ} \mathrm{C}$ for $1 \mathrm{~h}$ prior to removal of debris by centrifugation. Samples were diluted to a final concentration of $3.5 \%$ $\mathrm{HNO}_{3}$ and analysed by inductively coupled plasmamass spectrometry (ICP-MS) on an Agilent $7500 \mathrm{cx}$ ICP-MS (Adelaide Microscopy, University of Adelaide). Results are the mean $( \pm$ SEM) of at least three independent experiments, with the statistical significance determined using a two-tailed Student's $t$-test. 

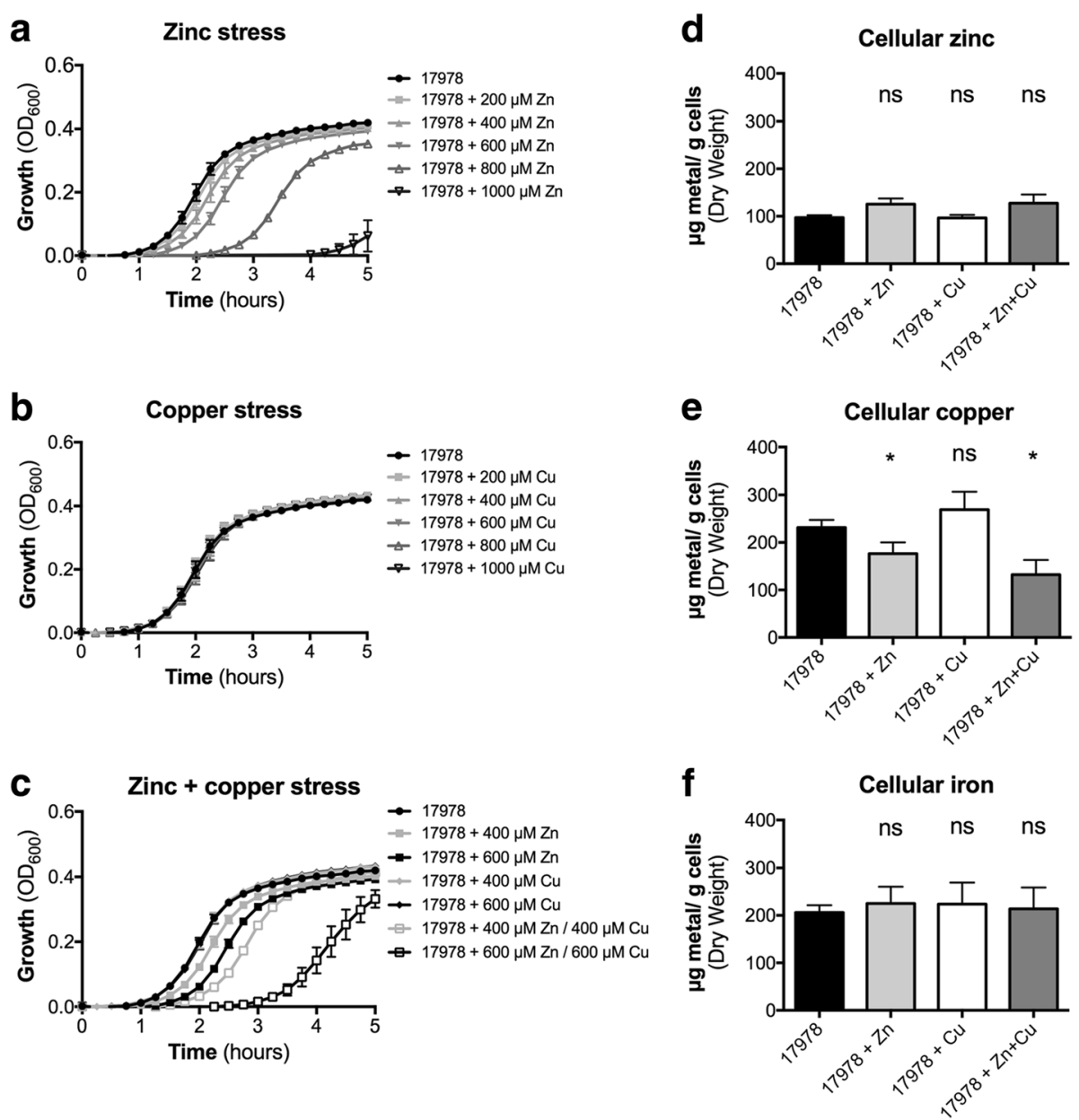

Fig. 1 The effect of $Z n$ and Cu stress on A. baumannii growth and metal ion homeostasis. Growth as determined by measuring the optical density at $600 \mathrm{~nm}\left(\mathrm{OD}_{600}\right)$ of A. baumannii strain ATCC 17978 under increasing concentrations of (a) $\mathrm{Zn}$, (b) Cu, or (c) $\mathrm{Zn}+\mathrm{Cu}(n \geq 3)$. Examination of the (d) $\mathrm{Zn}$, (e) Cu and (f) Fe levels in untreated cells and cells grown in the presence of $400 \mu \mathrm{M} \mathrm{Zn,} 400 \mu \mathrm{M}$ Cu or $400 \mu \mathrm{M} \mathrm{Zn}+400 \mu \mathrm{M}$ Cu. The cellular metal ion content (in microgram) per gram of desiccated cells was determined by ICP-MS. The data are the mean of at least biological triplicates $\left( \pm\right.$ SEM). Statistical analyses were performed using a two-tailed Student's $t$-test; $n s=$ not significant and ${ }^{*}=p<0.05$

\section{Comparative genomics}

Comparative BLASTP (2.2.28+) searches [51] of all annotated protein coding sequences in $A$. baumannii strains ATCC 17978, ATCC 19606T, D1279779, SDF, ACICU, AB0057, WM99c and 6870155, and Acinetobacter baylyi ADP1 were executed through the Proteinortho tool [52] to identify putative orthologous/paralogous proteins in each of the strains. Transport protein predictions were made using the Transporter Automated Annotation Pipeline (TransAAP [53]) to identify putative $\mathrm{Zn}$ and $\mathrm{Cu}$ transporters. Where orthologous/paralogous efflux transporters were identified between/within strains, genetic maps demonstrating the conservation of their coding gene and surrounding genes were generated using the Easyfig tool [54].

\section{RNA isolation and qRT-PCR}

For RNA extraction and qRT-PCR analysis, untreated or metal-stressed bacteria (LB supplemented with $400 \mu \mathrm{M}$
$\mathrm{ZnSO}_{4}, 400 \mu \mathrm{M} \mathrm{CuSO}_{4}$, or $400 \mu \mathrm{M} \mathrm{ZnSO} 4+400 \mu \mathrm{M}$ $\mathrm{CuSO}_{4}$ ) were harvested at mid log-phase and lysed in QiaZol (Qiagen) as described previously $[55,56]$. Following the addition of chloroform and phase separation, RNA was extracted and purified using a PureLink RNA Mini Kit (Thermo Fisher Scientific), according to the manufacturer's instructions. The total RNA samples were treated with DNase I (Roche) and qRT-PCR performed using the SuperScript III One-Step RT-PCR kit (Thermo Fisher Scientific) on a LC480 Real-Time Cycler (Roche). Transcription levels of genes were corrected to those obtained for GAPDH prior to normalization to the transcription levels observed for untreated $A$. baumannii cultures. Primer sequences are listed in Additional file 2. Results are the mean $( \pm$ SEM) of at least three independent experiments, with the statistical significance determined using a one-way ANOVA with Dunnett's post-test. 


\section{Superoxide dismutase activity assay}

Untreated and metal-stressed bacteria (LB supplemented with $400 \mu \mathrm{M} \mathrm{ZnSO}_{4}, 400 \mu \mathrm{M} \mathrm{CuSO}_{4}$, or $400 \mu \mathrm{M} \mathrm{ZnSO}_{4}$ $+400 \mu \mathrm{M} \mathrm{CuSO}{ }_{4}$ ) were harvested at mid log-phase $\left(\mathrm{OD}_{600}=0.7\right)$, washed in PBS and lysed by sonication on a BioRuptor (Diagenode). Following removal of cell debris by centrifugation, the SOD activity was determined according the manufacturer's protocol (Cayman). The data was corrected for the total protein input followed by normalisation against levels determined for untreated cells. The data are the means of at least biological triplicates $( \pm$ SEM), with the statistical significance determined using a Student's $t$-test.

\section{Fatty acid analyses}

Untreated or metal-stressed bacteria (LB supplemented with $400 \mu \mathrm{M} \mathrm{ZnSO}$, $400 \mu \mathrm{M} \mathrm{CuSO}$, or $400 \mu \mathrm{M}$ $\mathrm{ZnSO}_{4}+400 \mu \mathrm{M} \mathrm{CuSO}_{4}$ ) were harvested at mid logphase and analysed by gas chromatography at the School of Agriculture, Food and Wine, University of Adelaide, as previously described $[9,57]$. The data are the mean of five biological replicates $( \pm$ SEM), with the statistical significance determined using a one-way ANOVA with Dunnett's post-test.

\section{Macrophage killing assays}

THP-1 cells (ATCC TIB-202) were grown under atmospheric control $\left(5 \% \mathrm{CO}_{2}\right)$ at $37{ }^{\circ} \mathrm{C}$ in complete RPMI medium (RPMI with phenol red [Thermo Fisher Scientific], supplemented with $10 \%$ fetal bovine serum, $10 \mathrm{mM}$ HEPES, $30 \mu \mathrm{g} \cdot \mathrm{mL}^{-1}$ penicillin and $50 \mu \mathrm{g} \cdot \mathrm{mL}^{-1}$ streptomycin). Cell culture flasks $\left(25 \mathrm{~cm}^{2}\right.$; BD Falcon) were seeded with $3.5 \times 10^{6}$ THP-1 cells and differentiated by adding 100 ng. $\mathrm{mL}^{-1}$ phorbol 12-myristate 13acetate (PMA), prior to incubation for 3 days. Attached, differentiated, THP-1 cells (macrophages) were washed in complete RPMI and incubated with complete RPMI without added PMA to allow resting for a minimum of 2 days. Prior to challenge with $A$. baumannii, macrophages were detached using $1 \mathrm{~mL}$ StemPro Accutase (Thermo Fisher Scientific), washed in Hank's Balanced Salt Solution (HBSS; Thermo Fisher Scientific) and treated with either $50 \mu \mathrm{M} \mathrm{ZnSO}_{4}, 50 \mu \mathrm{M} \mathrm{CuSO}$, or $50 \mu \mathrm{M} \mathrm{ZnSO}_{4}+50 \mu \mathrm{M} \mathrm{CuSO}_{4}$ for $1 \mathrm{~h}$. Metalsupplemented macrophages were washed and diluted to $1.1 \times 10^{5}$ cells $\mathrm{mL}^{-1}$ in HBSS. A. baumannii cultures grown to mid-log phase $\left(\mathrm{OD}_{600}=0.7\right)$ were washed in HBSS and co-incubated with the macrophages at a multiplicity of infection of 10 for $60 \mathrm{~min}$. The colony forming units (CFUs) of $A$. baumannii were determined by plating onto LB agar plates and incubation at room temperature for $24 \mathrm{~h}$. The data was normalised for CFUs in the presence of untreated macrophages. The data are the mean of three biological replicates $( \pm$ SEM). The statistical differences between the CFUs determined in the presence of untreated and metal-treated macrophages were examined using a two-tailed Student's $t$-test.

\section{Results}

\section{Zn stress abrogates A. baumannii ATCC $17978 \mathrm{Cu}$} homeostasis

We assessed the impact of extracellular $\mathrm{Zn}$ and $\mathrm{Cu}$ ions on $A$. baumannii fitness by examining growth of $A$. baumannii strain ATCC 17978 in the presence of increasing concentrations of $\mathrm{ZnSO}_{4}$ and/or $\mathrm{CuSO}_{4}(200,400,600$, 800 and $1000 \mu \mathrm{M})$. We observed that $A$. baumannii ATCC 17978 was acutely sensitive to extracellular $\mathrm{Zn}$ abundance with $400 \mu \mathrm{M} \mathrm{Zn}$ supplementation resulting in a $\sim 30$ min growth delay (Fig. 1a). Bacterial fitness decreased further at higher $\mathrm{Zn}$ concentrations, with growth delays of approximately 1 and $2.5 \mathrm{~h}$ observed in 600 and $800 \mu \mathrm{M} \mathrm{Zn}$, respectively. By contrast, $\mathrm{Cu}$ stress had no apparent phenotypic effect on A. baumannii ATCC 17978 at any of the concentrations examined (Fig. 1b). The limited impact of $1000 \mu \mathrm{M} \mathrm{Cu}$ on the growth of $A$. baumannii corroborates observations from a previous study which examined copper stress in a nutrient limited media [58]. Treatment with both $\mathrm{Zn}+\mathrm{Cu}$ had a synergistic impact on $A$. baumannii ATCC 17978 growth (Fig. 1c) as the magnitude of growth delay was greater than that observed for the individual treatments with $\mathrm{Zn}$ (Fig. 1a) or Cu (Fig. 1b). This is in contrast to the effect of solid brass $(\mathrm{Zn}+\mathrm{Cu})$ on $A$. baumannii survival, which was shown to have a more moderate antimicrobial effect as compared to $\mathrm{Cu}$ alone [58].

We then investigated the effects of $\mathrm{Zn}, \mathrm{Cu}$ and $\mathrm{Zn}+$ $\mathrm{Cu}$ on metal ion accumulation in A. baumannii ATCC 17978 by ICP-MS. Metal content analysis was performed on cells grown in the presence of $400 \mu \mathrm{M} \mathrm{Zn}, 400 \mu \mathrm{M}$ $\mathrm{Cu}$, or $400 \mu \mathrm{M} \mathrm{Zn}+400 \mu \mathrm{M} \mathrm{Cu}$. The first row transition metal ions $\mathrm{Zn}, \mathrm{Cu}$ and $\mathrm{Fe}$ were the most abundant in $A$. baumannii (Additional file 3; Fig. 1d, e and f). Minor, but not significant $(p>0.05)$, increases in cellular accumulation of $\mathrm{Zn}$ were observed when cells were grown in the presence of $\mathrm{Zn}$ and $\mathrm{Zn}+\mathrm{Cu}$ (Fig. 1d). Similarly, treatment with $\mathrm{Cu}$ did not result in increased $\mathrm{Cu}$ accumulation (Fig. 1e). However, cellular $\mathrm{Cu}$ levels were significantly decreased in cells grown in the presence of $\mathrm{Zn}$ by comparison to untreated cells (Fig. 1e). Intriguingly, supplementing this condition with $\mathrm{Cu}$, i.e. $\mathrm{Zn}$ $+\mathrm{Cu}$ treatment, did not rescue the $\mathrm{Zn}$-induced $\mathrm{Cu}$ depletion. Instead, the combined treatment resulted in a further decrease in cellular $\mathrm{Cu}$ levels, greater than that observed for $\mathrm{Zn}$ treatment alone. The impact on $\mathrm{Cu}$ accumulation was specific, as the other first row transition metal ions, $\mathrm{Mn}$, cobalt $(\mathrm{Co})$, nickel $(\mathrm{Ni})$ and $\mathrm{Fe}$, were not significantly affected by any of the treatments (Fig. 1e; Additional file 3). 


\section{A. baumannii ATCC 17978 possesses a broad arsenal of putative $\mathrm{Zn}$ and $\mathrm{Cu}$ efflux systems}

Transporters associated with metal ion efflux serve crucial roles in preventing metal ion intoxication. We observed that in the presence of extracellular $\mathrm{Zn}$ and/or $\mathrm{Cu}$ stress, A. baumannii ATCC 17978 did not accumulate these metals at higher concentrations than untreated cells, which can be attributed, at least in part, to the action of metal ion efflux pathways. Here, we used TransAAP to identify putative $\mathrm{Zn}$ and $\mathrm{Cu}$ efflux systems encoded in A. baumannii ATCC 17978. We identified 13 efflux systems that belong to either the CDF family (TCDB: 2.A.4), P-type ATPase family (TCDB: 3.A.3), CorA metal ion transporter family (TCDB: 1.A.35), HME family of RND transporters (TCDB: 2.A.6.1), or CopB-type family of $\mathrm{Cu}$ exporters. These were then examined for their transcriptional responsiveness to $\mathrm{Zn}$ and/or $\mathrm{Cu}$ stress ( $400 \mu \mathrm{M}$ of each ion) as a hallmark of their potential contribution to metal ion homeostasis.
We observed that in A. baumannii ATCC 17978, extracellular $\mathrm{Zn}$ stress induced transcription of the genes encoding four of the 13 putative efflux systems (Fig. 2). The genes up-regulated included two CDF transporters, (A1S_0709, 2.9-fold; and A1S_1045, 5.0-fold), one HME efflux system (A1S_3217, 13.7-fold) and one P-type ATPase (A1S_2939, 4.7-fold). Growth in the presence of $\mathrm{Cu}$ stress resulted in the up-regulation of five of the 13 putative $\mathrm{Zn}$ or $\mathrm{Cu}$ transport systems. These included the Zn-induced CDF family transporter A1S_0709 (2.4-fold), and the P-type ATPase, A1S_2939 (12.0-fold). In addition, the HME family transporter A1S_2932 (2.9fold), the CopB-like outer membrane protein A1S_2935 (80.0-fold) and the P-type ATPase A1S_1217 (29.2-fold) were specifically up-regulated in the presence of $\mathrm{Cu}$. Growth in the presence of both $\mathrm{Zn}$ and $\mathrm{Cu}$ stress induced most, but not all, of the efflux systems observed to be up-regulated under the individual stresses of $\mathrm{Zn}$ or $\mathrm{Cu}$ (Fig. 2). Intriguingly, although the CDF family

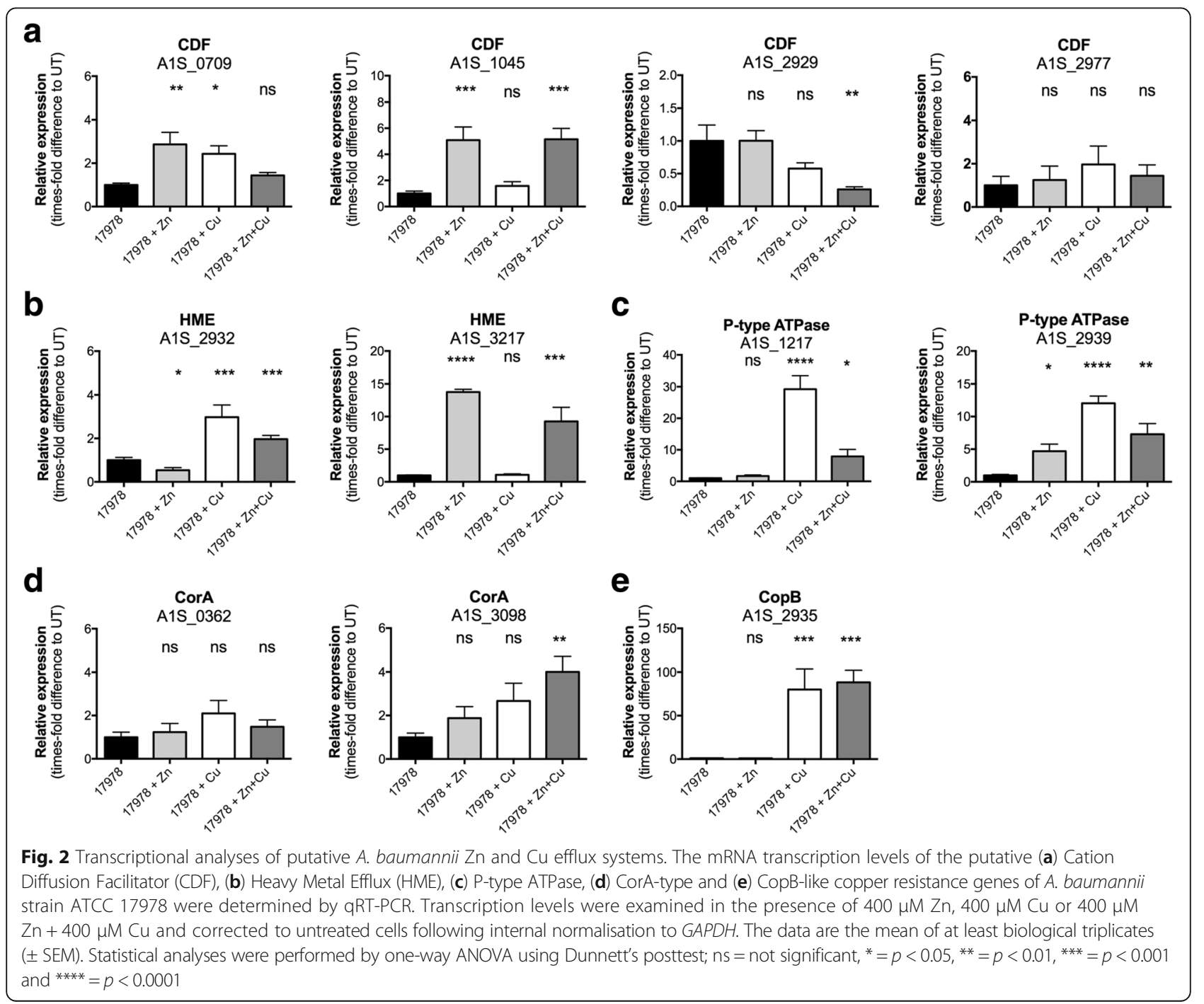


transporter A1S_0709, was up-regulated in the presence of the individual ion stress, it was transcriptionally unresponsive in the presence of $\mathrm{Zn}+\mathrm{Cu}$. In addition, the CDF family transporter A1S_2929 was significantly down-regulated when cells were stressed with $\mathrm{Zn}+\mathrm{Cu}$ (3.9-fold), yet transcription was not altered when treated with $\mathrm{Zn}$ or $\mathrm{Cu}$ alone. By contrast, the CorA-type exporter A1S_3098 that was unresponsive to the individual $\mathrm{Zn}$ or $\mathrm{Cu}$ stresses was observed to be up-regulated (4.0fold) when treated with both ions.

Our observations corroborate "omics" analyses of $\mathrm{Zn}$ and $\mathrm{Cu}$ stress in other bacteria, where proteomic/transcriptomic profiles show significant overlap between the two independent stresses [59-61]. Collectively, our data show that A. baumannii ATCC 17978 possesses a number of efflux systems associated with resistance to $\mathrm{Zn}$ and/or $\mathrm{Cu}$ ions. The overlap between $\mathrm{Zn}$ and $\mathrm{Cu}$ resistance profiles revealed two metal ion efflux systems that may have poly-specific cation efflux properties. However, it is also possible that one or both of these pathways may be $\mathrm{Cu}$-specific and activated inappropriately under $\mathrm{Zn}$ stress, resulting in the $\mathrm{Cu}$-depletion phenotype observed.

\section{Comparative analysis of $\mathrm{Zn}$ and $\mathrm{Cu}$ resistance mechanisms in diverse Acinetobacter strains}

Previous studies of the A. baumannii antibiotic resistance and virulence mechanisms have revealed major genomic variation between strains $[4,62]$. Therefore, we examined the presence of putative $\mathrm{Zn}$ and/or $\mathrm{Cu}$ efflux systems across a collection of highly diverse strains previously analysed by our groups [4], as well as the environmental isolate Acinetobacter baylyi ADP1. The number of genes encoding putative $\mathrm{Zn}$ and/or $\mathrm{Cu}$ efflux systems identified ranged between eight (strain SDF) and 18 (strain AB6870155) in each of the strains examined, but all were chromosomally encoded. To determine if the putative efflux systems identified were conserved between strains, and whether conserved transporters were encoded in the same genomic locations, comparative blast searches were conducted between the genomes of the respective strains. These searches revealed a complement of seven genes encoding putative $\mathrm{Zn}$ and/or $\mathrm{Cu}$ efflux systems that were conserved in all nine of the strains studied, including $A$. baylyi ADP1, albeit at lower sequence identity. These included the CDF transporters orthologous to A1S_0709, A1S_1045 and A1S_3214, P-ATPase system orthologous to A1S_1217, HME system orthologous to A1S_3217, and CorA family transporters orthologous to A1S_0362 and A1S_3098 (Fig. 3). A. baylyi ADP1 only encoded one putative $\mathrm{Zn}$ and/or $\mathrm{Cu}$ efflux system that was not found in the A. baumannii strains, a CDF family transporter, ACIAD0449. The significant conservation of $\mathrm{Zn}$ and/or $\mathrm{Cu}$ efflux proteins between A. baylyi ADP1 and the $A$. baumannii strains is notable, and suggests that $\mathrm{Zn}$ and $\mathrm{Cu}$ efflux are core functions that have been conserved since before the divergence of these species.

A. baumannii SDF features the least number of genes encoding putative $\mathrm{Zn}$ and/or $\mathrm{Cu}$ efflux systems (8), which is likely due to the increased prevalence of insertion sequence elements (IS) and extensive genome degradation in this strain. At least two metal resistance mechanisms found in all other strains $(\operatorname{cop} A$ and $\operatorname{cop} B)$, orthologous to A1S_0707 and A1S_0708 in ATCC 17978 , have been deleted or insertionally disrupted in the genome of SDF by an IS (Fig. 3b). These genes appear to be encoded in a single operon with the CDF transporter gene orthologous to A1S_0709. Therefore, expression of this CDF transporter could also be affected by this IS insertion. Additionally, an IS is present in the SDF genome between the genes encoding two conserved putative metal ion efflux systems listed above, orthologs of A1S_3214 and A1S_3217 (Fig. 3g). As a consequence, the expression levels of the A1S_3214 ortholog in strain SDF may be affected by the insertion of this IS into its putative regulatory region. Five strains harboured more than ten genes encoding putative $\mathrm{Zn}$ and/or $\mathrm{Cu}$ efflux components, including ATCC 17978 (17), ATCC $19606 \mathrm{~T}$ (11), AB0057 (16), AB6870155 (18), and ACICU (11). Each of these strains carried genes encoding putative $\mathrm{Zn}$ and/or $\mathrm{Cu}$ efflux systems in chromosomal regions that are likely to have been acquired horizontally on mobile genetic elements. The largest of these elements is a Cu-resistance island (Fig. 3h), which has been previously reported in A. baumannii strain LAC-4 [63]. In addition to strain ATCC 17978, strains AB0057 and AB6870155 also encode part of this island, which has inserted into the dusA locus [64]. Furthermore, genes orthologous to the CDF family system encoded by A1S_2929 in the ATCC $17978 \mathrm{Cu}$-resistance island are also found in AB0057, AB6870155, ATCC 19606T and ACICU, but at different loci (Fig. 3i). Notably, AB6870155 carries three copies of this transporter. As mentioned above, AB6870155 encodes the greatest number of putative $\mathrm{Zn}$ and/or $\mathrm{Cu}$ efflux systems of the strains studied, suggesting that this strain may have frequently encountered elevated levels of metal ions during its evolution. All other $\mathrm{Zn}$ and/or $\mathrm{Cu}$ resistance mechanisms, i.e. those not associated with the $\mathrm{Cu}$ resistance island, may be considered part of the core metal ion resistome.

\section{Growth characteristics of diverse Acinetobacter strains in the presence of $\mathrm{Zn}$ and $\mathrm{Cu}$}

Given the differences in the number and type of putative metal ion efflux systems encoded by the Acinetobacter strains, we investigated whether this had a phenotypic 


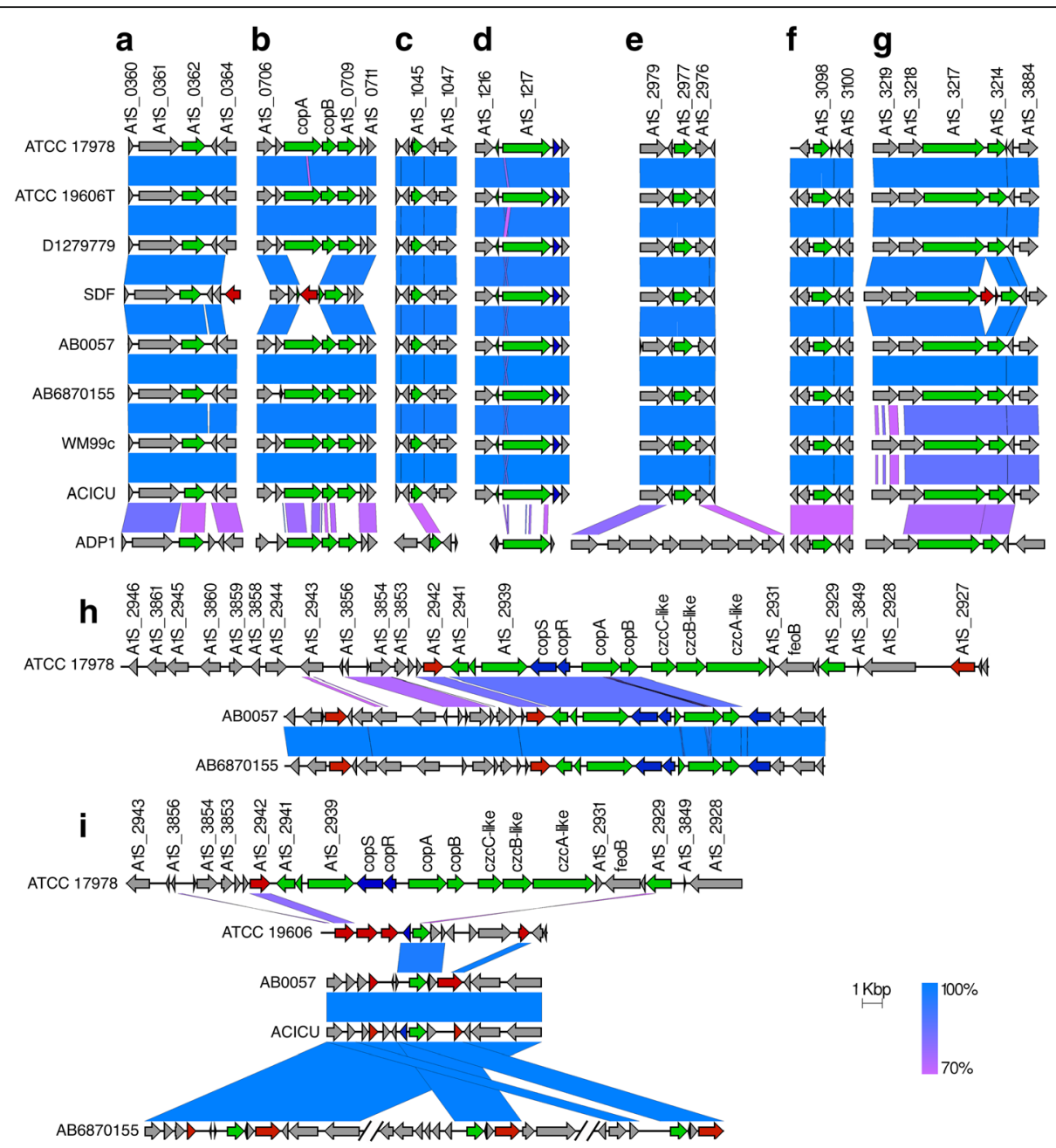

Fig. 3 Comparative analysis of the Acinetobacter $\mathrm{Zn}$ and $\mathrm{Cu}$ efflux systems. Genomic regions containing putative efflux systems of the Acinetobacter strains are shown in panels (a-i). Putative efflux systems were identified using the TransAAP [53] and subsequently aligned and visualised using the Easyfig tool [54]. Genes encoding putative Zn or Cu efflux systems are coloured in green, putative regulators in proximity to these transporters are coloured in blue, genes that may encode for DNA mobilization proteins are coloured red, and other genes are coloured grey. The percentage identity between the regions being compared is indicated by shading

impact on their resistance profiles to $\mathrm{Zn}$ and/or $\mathrm{Cu}$. Here, we examined growth of each of the A. baumannii strains and A. baylyi ADP1 in the presence of $400 \mu \mathrm{M}$ $\mathrm{Zn}, 600 \mu \mathrm{M} \mathrm{Zn}, 400 \mu \mathrm{M} \mathrm{Cu}, 600 \mu \mathrm{M} \mathrm{Cu}, 400 \mu \mathrm{M} \mathrm{Zn}+$ $400 \mu \mathrm{M} \mathrm{Cu}$, and $600 \mu \mathrm{M} \mathrm{Zn}+600 \mu \mathrm{M} \mathrm{Cu}$. Although growth in the presence of $400 \mu \mathrm{M} \mathrm{Cu}$ was examined, the majority of $A$. baumannii strains were unaffected by this concentration and so we have excluded this condition from further analysis. We observed that all strains experienced a growth delay in the presence of $600 \mu \mathrm{M} \mathrm{Zn}$ (Fig. 4). However, with the exception of the SDF strain, the $\mathrm{Zn}$-induced growth delays were generally less than that observed for the ATCC 17978 strain. This was unexpected and cannot be solely explained by comparative analyses of the $\mathrm{Zn}$ efflux systems described above. The other strains also showed resistance to extracellular $\mathrm{Cu}$ comparable to the ATCC 17878 strain. However, the SDF strain was a notable exception with no growth observed in the presence of $600 \mu \mathrm{M} \mathrm{Cu}$ (Fig. 4). This suggests that the $\operatorname{cop} A$ and $\operatorname{copB} \mathrm{Cu}$ resistance mechanisms (orthologs of A1S_0707 and A1S_0708, respectively, in the ATCC 17978 strain), which are disrupted by IS elements, could have a prominent role in Acinetobacter $\mathrm{Cu}$ resistance (Fig. 3). The combination of $\mathrm{Zn}+\mathrm{Cu}$ stress resulted in a synergistic growth delay in most $\mathrm{Aci}$ netobacter strains. Although, similar to the impact of $\mathrm{Zn}$ stress, the majority of strains were affected less by $\mathrm{Zn}+$ $\mathrm{Cu}$ stress by comparison with the ATCC 17978 strain. The sole exception was the SDF strain, which was hyper-susceptible to the combination of $\mathrm{Zn}+\mathrm{Cu}$ stress.

Taken together, these data suggest that CopA/CopBtype copper resistance mechanisms have a prominent 


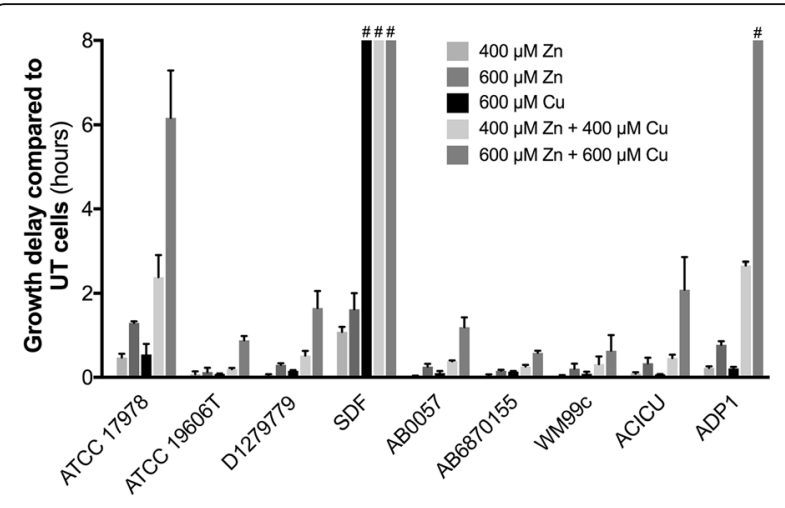

Fig. 4 The effects of $\mathrm{Zn}$ and/or Cu stress on other Acinetobacter strains. Strains of Acinetobacter were diluted to $\mathrm{OD}_{600}=0.01$ from stationary phase cultures and grown without metal ion stress (untreated; UT), or in the presence of $400 \mu \mathrm{M} Z \mathrm{n}, 600 \mu \mathrm{M} \mathrm{Zn,}$ $600 \mu \mathrm{M} \mathrm{Cu}, 400 \mu \mathrm{M} Z \mathrm{Zn}+400 \mu \mathrm{M}$ Cu, or $600 \mu \mathrm{M} Z \mathrm{Zn}+600 \mu \mathrm{M}$ Cu. The effect of metal ion stress was examined by comparing the $\mathrm{EC}_{50}$, which was calculated from $\mathrm{OD}_{600}$ measurements taken every 6 mins. The results are the average of at least four replicate cultures of at least two distinct biological samples. " indicates no growth detected within $18 \mathrm{~h}$

role in $\mathrm{Cu}$ tolerance in Acinetobacter species, based on the reduced $\mathrm{Cu}$ resistance in strain SDF. However, the genomic and phenotypic analyses do not reveal a specific efflux system or type of efflux pathway as being a major determinant of $\mathrm{Zn}$ resistance. As the combination of metal ion stresses acted in a synergistic manner in all strains, the underlying cause of this phenotype appears to be conserved amongst all strains.

\section{$\mathrm{Zn}$ and Cu contribute to A. baumannii ATCC 17978 resistance to reactive oxygen species}

Metal ion intoxication is often associated with an increased risk of susceptibility to intracellular reactive oxygen species (ROS). Zinc, although not directly redox active, has been proposed to contribute to oxidative stress via the displacement of Fe from Fe-S clustercontaining proteins [21]. By contrast, $\mathrm{Cu}$, which is reduced to $\mathrm{Cu}(\mathrm{I})$ in the cytoplasm, is highly redox active and acutely toxic at elevated intracellular concentrations [65]. Despite this, both $\mathrm{Zn}$ and $\mathrm{Cu}$ ions are crucial cofactors in the $\mathrm{Cu}-\mathrm{Zn}$ superoxide dismutase $(\mathrm{Cu}-\mathrm{Zn}$ SOD), which detoxifies superoxide anions $\left(\mathrm{O}_{2}^{-{ }^{-}}\right)$. Thus we sought to examine the impact of extracellular $\mathrm{Zn}$ and/or $\mathrm{Cu}$ on the resistance of $A$. baumannii to $\mathrm{O}_{2}^{-{ }^{-}}$and $\mathrm{H}_{2} \mathrm{O}_{2}$. Here, we examined the growth phenotype of $A$. baumannii ATCC 17978 in the presence of $400 \mu \mathrm{M} \mathrm{Zn}$ and/or $\mathrm{Cu}$ and oxidative stress.

Our analyses revealed that $\mathrm{Zn}$-mediated depletion of cellular $\mathrm{Cu}$ in $A$. baumannii increased the bacterium's susceptibility to intracellular $\mathrm{O}_{2}^{--}$(media supplemented with $40 \mu \mathrm{M}$ paraquat) (Fig. 5a and Additional file 1A). Detoxification of $\mathrm{O}_{2}^{--}$in A. baumannii ATCC 17978 is facilitated by a putative Zn-Cu-SOD (A1S_3143) and a previously characterised Fe/Mn SOD (Fe/Mn-SOD) (A1S_2343) [66]. Whilst $\mathrm{Cu}-\mathrm{Zn}$-SOD proteins have been reported to localise to the periplasm in other Gramnegative bacteria such as E. coli and Salmonella [67, 68], the $A$. baumannii $\mathrm{Cu}-\mathrm{Zn}$-SOD sequence lacks a signal sequence for periplasmic targeting (Additional file 4), suggesting a cytoplasmic localisation. Interestingly, the total cellular SOD activity was reduced to a similar extent in cells under $\mathrm{Zn}$ (17\%), $\mathrm{Cu}(23 \%)$ and $\mathrm{Zn}+\mathrm{Cu}$ stress (24\%) (Fig. 5b). Although this does not explain the growth perturbation observed, the total SOD activity inversely correlates with the transcription levels of the $\mathrm{Cu}-\mathrm{Zn}$-SOD, which was found to be up-regulated to a similar extent under all metal stress conditions examined ( 4-fold; Fig. 5c). Transcriptional analysis of the Fe/Mn-SOD did not reveal any differences (Fig. 5d). Metal stress was also demonstrated to significantly affect the resistance of $A$. baumannii to $\mathrm{H}_{2} \mathrm{O}_{2}$ (Fig. 5e and Additional file $1 \mathrm{~B}$ ). $\mathrm{Cu}$ supplementation of $A$. baumannii resulted in a significant increase in sensitivity of $\mathrm{H}_{2} \mathrm{O}_{2}$, with $\mathrm{Cu}$ depletion (via $\mathrm{Zn}$ or $\mathrm{Zn}+\mathrm{Cu}$ supplementation) causing a significant decrease in $\mathrm{H}_{2} \mathrm{O}_{2}$ sensitivity. Collectively, our analyses show that both $\mathrm{Zn}$ and $\mathrm{Cu}$ ions significantly influence oxidative stress management in $A$. baumannii ATCC 17978.

\section{$\mathrm{Zn}$ and $\mathrm{Cu}$ play key roles in modulating $A$. baumannii membrane biology}

Bacterial cell membranes serve a key role in defence against environmental stresses. Metal ions and oxidative stresses can exert significant and potentially deleterious effects on bacterial cell membrane composition and integrity [69]. Predominantly, this arises through modulation of abundance of unsaturated fatty acids, which impacts membrane fluidity. Here, we sought to examine the impact of metal ion stress on the fatty acid content of mid log-phase A. baumannii ATCC 17978 cells grown in presence of $400 \mu \mathrm{M} \mathrm{Zn}$ and/or Cu (Fig. 6a-d). Our analyses showed that A. baumannii ATCC 17978 membranes consist of four major fatty acids, which include two saturated fatty acids (16:0 and 18:0) and two mono-unsaturated fatty acids (16:1n-7 and 18:1n-9) (Fig. 6a-d) [9]. Metal ion stress caused significant alterations in the abundance of the mono-unsaturated fatty acids. $\mathrm{Zn}$ and $\mathrm{Zn}+\mathrm{Cu}$ stress induced a significant increase in the abundance of 16:1n-7 mono-unsaturated fatty acids. By contrast, only the combination of $\mathrm{Zn}+$ $\mathrm{Cu}$ stress was associated with a significant reduction $(1.3 \%)$ in the abundance of $18: 1 n-9$ mono-unsaturated fatty acids, by comparison with untreated cells. Even these relatively minor changes in the fatty acid composition of the cell membrane will influence membrane fluidity and have been proposed to be one mechanism 

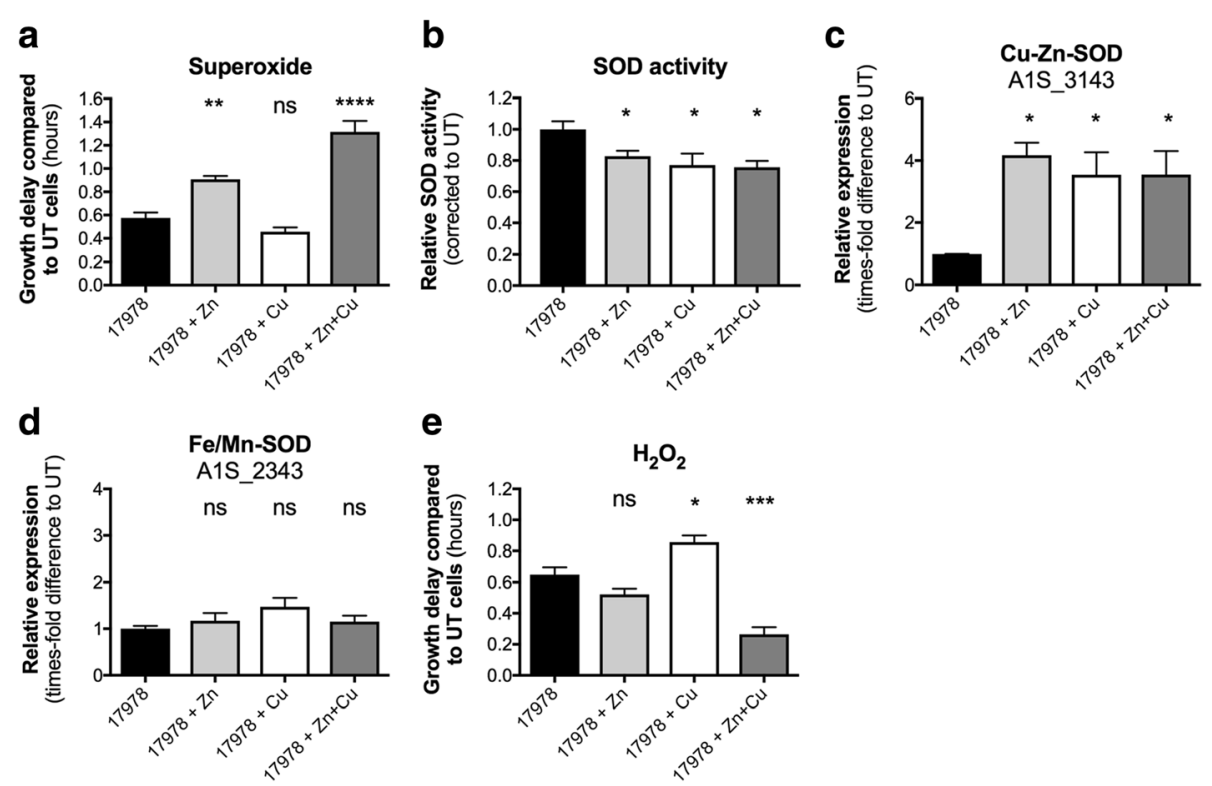

Fig. 5 The effect of $\mathrm{Zn}$ and $\mathrm{Cu}$ treatment on the resistance of $\mathrm{A}$. baumannii to oxidative stress. The effect of (a) $40 \mu \mathrm{M}$ paraquat and (e) $160 \mu \mathrm{M} \mathrm{H}_{2} \mathrm{O}_{2}$ on A. baumannii strain ATCC 17978 grown in the presence of $400 \mu \mathrm{M} Z n, 400 \mu \mathrm{M} \mathrm{Cu}, 400 \mu \mathrm{M} \mathrm{Zn}+400 \mu \mathrm{M}$ Cu, or without added metal ions, was determined by measuring the optical density at $600 \mathrm{~nm}\left(\mathrm{OD}_{600}\right)$. The growth delay between untreated (UT) and paraquat- $\mathrm{Or}_{2} \mathrm{O}_{2}$-treated cells was examined by comparing the $\mathrm{EC}_{50}$ under each relevant metal ion stress condition. Statistical analyses were performed using a one-way ANOVA. b The total SOD activity of mid-log phase cells (untreated, $400 \mu \mathrm{M} Z \mathrm{Zn}, 400 \mu \mathrm{M}$ Cu or $400 \mu \mathrm{M} Z n+400 \mu \mathrm{M} \mathrm{Cu}$ ) was determined. Data were corrected for total protein content, followed by normalisation to untreated cells. Statistical analyses were performed using a Student's t-test. The mRNA transcription levels of (c) Cu-Zn superoxide dismutase (Cu-Zn-SOD; A1S_3143), (d) Fe/Mn superoxide dismutase (Fe/Mn-SOD; A1S_2343) were determined by qRT-PCR. The transcription levels examined in the presence of $400 \mu \mathrm{M} Z n, 400 \mu \mathrm{M}$ Cu or $400 \mu \mathrm{M} Z n+400 \mu \mathrm{M}$ Cu were corrected to untreated cells following internal normalisation to GAPDH. The data are the mean of at least biological triplicates $( \pm$ SEM). Statistical analyses were performed by one-way ANOVA using Dunnett's posttest. For all statistical analyses; ns = not significant, ${ }^{*}=p<0.05,{ }^{* *}=p<0.01,{ }^{* *}=p<0.001$ and ${ }^{* * *}=p<0.0001$

of bacterial adaption to extracellular stress [69]. Accordingly, we examined how alterations in cell membrane composition, as a function of metal ion stress, influenced resistance to arachidonic acid, a long chain polyunsaturated fatty acid with known antimicrobial activity [70]. Consistent with the observations of metal ion stress on membrane fatty acid composition, A. baumannii grown in the presence of $400 \mu \mathrm{M} \mathrm{Zn}+\mathrm{Cu}$ showed increased susceptibility to arachidonic acid, with a significantly increased growth delay, by comparison to untreated cells (Fig. 6e and Additional file 1C). Whether this is directly attributable to the decreased abundance of the 18:1n-9 mono-unsaturated fatty acids in these membranes requires further investigation.

\section{$\mathrm{Zn}$ and $\mathrm{Cu}$ contribute to macrophage-mediated killing of \\ A. baumannii}

Macrophages are known to utilize a broad range of antimicrobial compounds to prosecute killing of bacterial pathogens, including, $\mathrm{Zn}, \mathrm{Cu}, \mathrm{H}_{2} \mathrm{O}_{2}, \mathrm{O}_{2}^{--}$, and arachidonic acid. Here, we investigated the effect of $\mathrm{Zn}$ and/or $\mathrm{Cu}$ on the macrophage-mediated killing of $A$. baumannii ATCC 17978. Human THP-1 derived macrophages were supplemented with the metal ions prior to infection with untreated A. baumannii cells. We observed that $\mathrm{Zn}$ - treated macrophages were significantly compromised in their ability to kill $A$. baumannii, resulting in an $18 \%$ higher survival rate, by comparison to bacteria exposed to untreated macrophages (Fig. 7). By contrast, $\mathrm{Cu}$-treated macrophages showed an improvement in bacterial killing (10\% lower bacterial survival rate), by comparison with untreated macrophages (Fig. 7). However, macrophages treated with $\mathrm{Zn}+\mathrm{Cu}$ did not show a significant alteration in the efficiency of bacterial killing. Overall, these data indicate that the $\mathrm{Zn}$ and $\mathrm{Cu}$ status of macrophages can directly influence the killing of A. baumannii, although the molecular basis is likely to be highly complex and warrants significant further investigation.

\section{Discussion}

Bacteria tightly regulate the intracellular concentrations of metal ions to balance their necessity for a range of cellular functions, against the lethal consequences of metal overload and intoxication. In this study, we examined the effects of $\mathrm{Zn}$ and $\mathrm{Cu}$ toxicity on A. baumannii fitness and identified numerous molecular mechanisms associated with management of these stresses, including a range of putative metal ion efflux systems. Exponential growth of A. baumannii strain ATCC 17978 was delayed 
a

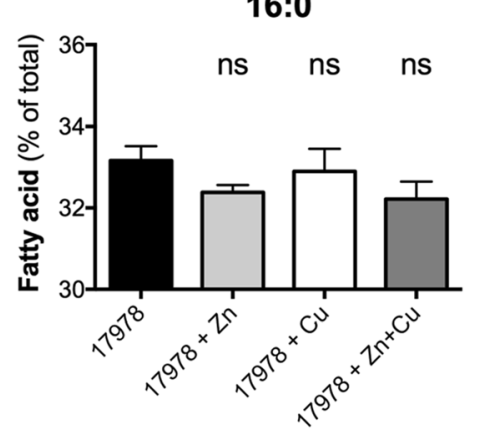

b

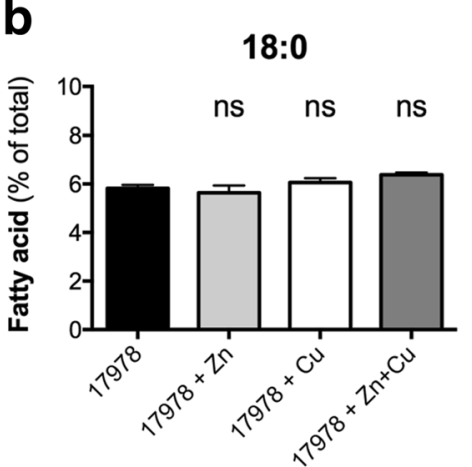

C

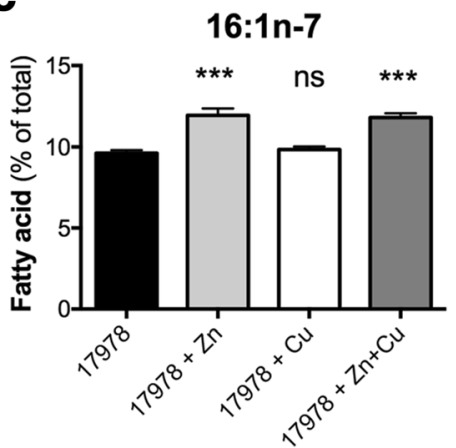

d

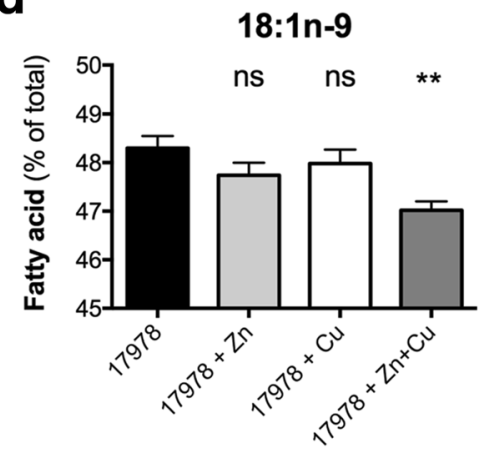

e

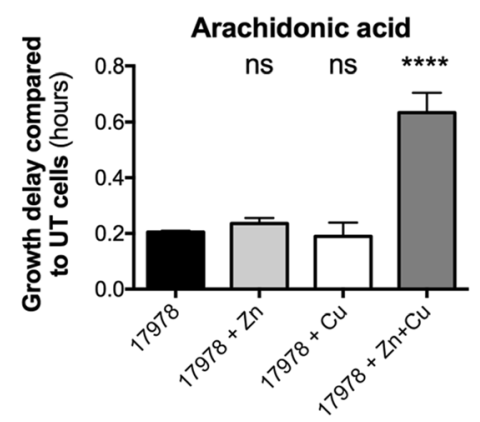

Fig. 6 The effects of $\mathrm{Zn}$ and Cu on A. baumannii membrane biology. The major cellular fatty acid constituents of A. baumannii strain ATCC 17978, grown in the presence of $400 \mu \mathrm{M} \mathrm{Zn,} 400 \mu \mathrm{M} \mathrm{Cu}, 400 \mu \mathrm{M} Z n+400 \mu \mathrm{M} \mathrm{Cu}$, or without added metal ions were determined by gas chromatography. The abundance of fatty acids, expressed as percentage of total cellular fatty acids, is (a) 16:0 (b) 18:0, (c) 16:1n-7 and (d) 18:1n-7. The data are the mean of at least biological triplicates ( \pm SEM). Statistical analyses were performed by one-way ANOVA using Dunnett's posttest; ns = not significant, $*^{*}=p<0.01$ and ${ }^{* *}=p<0.001$. e The susceptibility of A. baumannii strain ATCC 17978 to arachidonic acid (20:4n-6) grown in the presence of $400 \mu \mathrm{M} \mathrm{Zn}, 400 \mu \mathrm{M} \mathrm{Cu}, 400 \mu \mathrm{M} Z n+400 \mu \mathrm{M} \mathrm{Cu}$, or without added metal ions was determined by measuring the optical density at $600 \mathrm{~nm}$ $\left(\mathrm{OD}_{600}\right)$. The growth delay between untreated and arachidonic acid-treated cells was examined by comparing the $\mathrm{EC}_{50}$ under each relevant metal ion stress condition. The data are the mean of at least biological triplicates $( \pm$ SEM). Statistical analyses were performed by one-way ANOVA using Dunnett's posttest; ns = not significant and ${ }^{* * *} p<0.0001$

to a greater extent by $\mathrm{Zn}$ than by $\mathrm{Cu}$, a phenotype that was shared by six other clinical A. baumannii species from different clonal groups, and by the environmental strain A. baylyi ADP1. Only strain SDF, isolated from a human associated louse, was found to be more susceptible to $\mathrm{Cu}$ than to the equivalent concentration of $\mathrm{Zn}$, which may be attributable to the loss of the $\operatorname{cop} A B$ genes in this strain. Examination of cellular metal ion abundance in strain ATCC 17978 showed that under Zn or
$\mathrm{Cu}$ stress, neither metal was accumulated at significantly higher levels. This indicates that $A$. baumannii either prevents their uptake or is able to efficiently efflux the ions from the cell.

Species of the Acinetobacter genus have adapted to survive in a wide variety of environments, which is likely to have contributed to the presence of the substantial number of metal ion efflux systems within their genomes. Using our comprehensive bioinformatic 


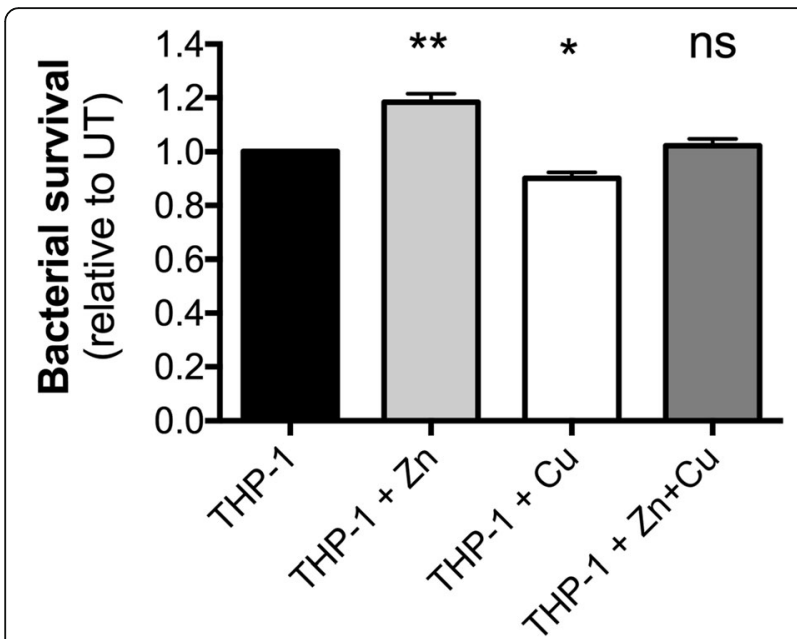

Fig. 7 The effect of $\mathrm{Zn}$ and $\mathrm{Cu}$ on macrophage-mediated killing of A. baumannii. The survival of A. baumannii ATCC 17978 cells in the presence of THP-1 human monocyte-derived macrophages that were either treated with $50 \mu \mathrm{M} Z n, 50 \mu \mathrm{M}$ Cu or $50 \mu \mathrm{M} Z n+50 \mu \mathrm{M}$ Cu was compared to survival of $A$. baumannii ATCC 17978 cells in the presence of untreated THP-1 cells. The data are the mean of biological triplicates $( \pm$ SEM). Statistical analyses were performed using a two-tailed Student's $t$-test; $\mathrm{ns}=$ not significant, ${ }^{*}=p<0.05$ and ${ }^{* *}=p<0.01$

membrane transporter identification pipeline, we identified a large number of these efflux systems, which may be responsible for translocating $\mathrm{Zn}$ and/or $\mathrm{Cu}$ from the cytoplasm to the periplasm and/or extracellular space in A. baumannii. Interestingly, subsequent comparative analyses demonstrated that most of these putative metal resistance systems are highly conserved between diverse $A$. baumannii strains, as well as with the environmental isolate $A$. baylyi ADP1. This suggests that these systems have played a crucial role in survival since the divergence of these Acinetobacter species. Nonetheless, some strains encoded considerably more putative metal ion efflux systems than others, typically on putative mobile elements that have been inserted into the chromosome. This additional metal ion efflux capacity suggests that their ancestral strains may have existed in metal-contaminated environments. Insight into the likely substrate specificities of the putative metal ion efflux systems was gained by transcriptional profiling in response to $\mathrm{Zn}$ and/or $\mathrm{Cu}$ stress. Based on transcriptional activation, the CDFs A1S_0709 ( 3-fold up-regulated) and A1S_1045 ( 5fold up-regulated), the P-type ATPase A1S_2939 ( 4fold up-regulated) and the HME A1S_3217 ( 14-fold up-regulated) are likely to be involved in $\mathrm{Zn}$ efflux in $A$. baumannii strain ATCC 17978 (Figs. 2 and 8). However, since A1S_0709 and A1S_2939 are each positioned in the same loci as $\mathrm{Cu}$-resistance mechanisms and both genes are also transcriptionally activated by
$\mathrm{Cu}$ stress ( 2 -fold and $\sim 12$-fold, respectively), their importance in $\mathrm{Zn}$ export is questionable. Rather, based on transcriptional profiling and conservation across the species, and to some extent genus, our analyses suggest the major $\mathrm{Zn}$ efflux systems in A. baumannii to be the CDF encoded by A1S_1045 and the HME family system encoded by A1S_3217.

Strain ATCC 17978 possesses three distinct putative $\mathrm{Cu}$-resistance mechanisms on its proposed $\mathrm{Cu}$-resistance island, including the P-type ATPase A1S_2939 ( 12-fold up-regulated), HME A1S_2932 ( 3-fold upregulated) and CopB A1S_2935 ( 80-fold up-regulated) (Figs. 2 and 8). Although highly transcriptionally responsive to $\mathrm{Cu}$, the $\mathrm{Cu}$-resistance island is unlikely to be essential for survival under high levels of $\mathrm{Cu}$ stress, as strain D1279779, which lacks all components of this island, displays a similar $\mathrm{Cu}$ resistance profile to the other strains examined in this study. The P-type ATPase A1S_1217 and its putative divergently transcribed $\mathrm{Cu}$ chaperone $\operatorname{copZ}$ (A1S_3627) were heavily up-regulated in response to $\mathrm{Cu}$ stress (A1S_1217 30-fold, and A1S_3627 19-fold [data not shown]) and are highly conserved across the strains examined in this study (Fig. 3d). Although this system can also be found in the highly $\mathrm{Cu}$-susceptible strain SDF, a potentially critical difference between the SDF strain and all other strains included in this study, is the lack of a CopAB Cu-resistance mechanism (either A1S_0707A1S_0708 or A1S_2936-A1S_2935). Therefore, the periplasmic $\mathrm{Cu}$ oxidase/cupredoxin (CopA) and the outer membrane exporter (CopB) appear critical for dealing with the $\mathrm{Cu}$ translocated from the cytoplasm to the periplasm by the inner membrane P-type ATPase A1S_1217.

Previous studies have shown that growth perturbations induced by metal ion stress can be attributed to disruption of cellular metal ion homeostasis, commonly resulting from protein mismetallation [27, 71]. Upon examination of the effect of $\mathrm{Zn}$ or $\mathrm{Cu}$ stress on the abundance of other first row transition metals, we found that $\mathrm{Zn}$ caused a significant depletion of $\mathrm{Cu}$ in $A$. baumannii, whereas high extracellular $\mathrm{Cu}$ did not significantly affect cellular metal ion levels. The effect of $\mathrm{Zn}$ stress on cellular $\mathrm{Cu}$ was found to be specific, as the accumulation of other metal ions, such as Fe and $\mathrm{Mn}$, was not altered. $\mathrm{Zn}$ toxicity is a widely studied topic, but to our knowledge this is the first report of Zn causing an imbalance in cellular $\mathrm{Cu}$ levels in any organism.

To determine whether $\mathrm{Cu}$ depletion in the presence of elevated $\mathrm{Zn}$ abundance could be rescued by the addition of excess $\mathrm{Cu}$, we examined the effect of equimolar concentrations of $\mathrm{Zn}$ and $\mathrm{Cu}(400 \mu \mathrm{M})$ on $A$. baumannii growth and metal ion homeostasis. Surprisingly, instead of an increase in $\mathrm{Cu}$, cellular $\mathrm{Cu}$ levels in A. baumannii strain ATCC 17978 were further 


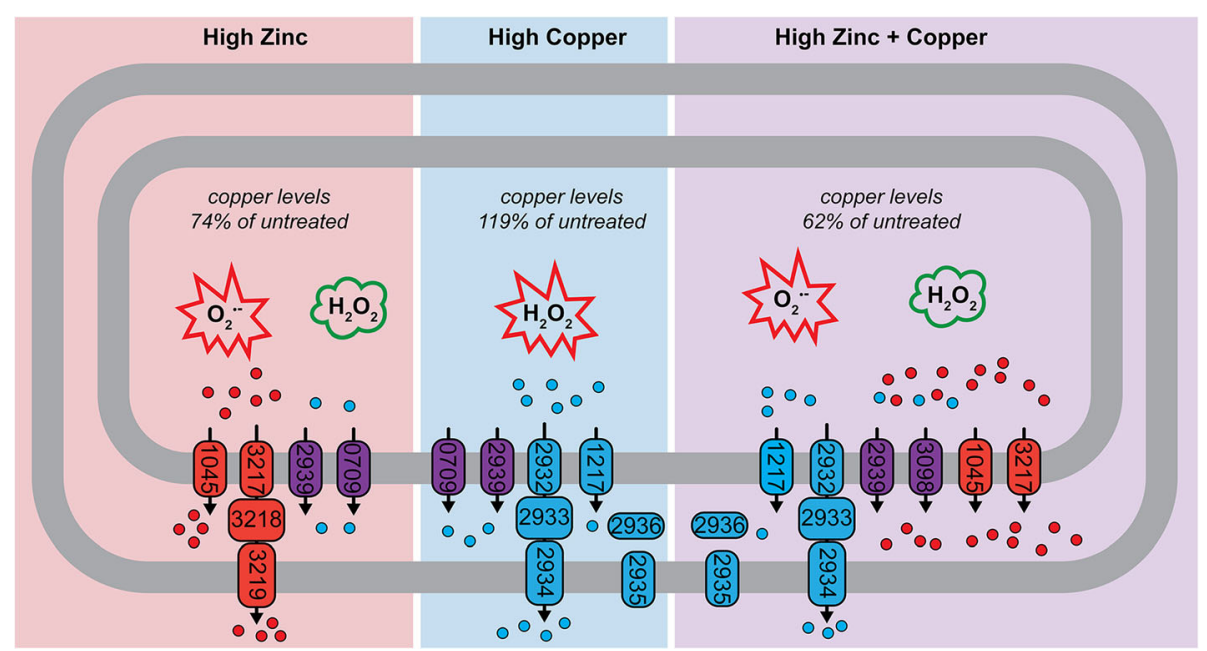

Fig. 8 An overview of the cellular responses of A. baumannii to Zn and Cu stress. Cartoon representation of A. baumannii ATCC 17978 under

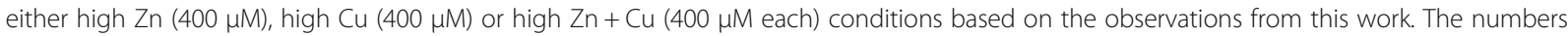
within the efflux systems (ovals) are the locus-tags for A. baumannii strain ATCC 17978, excluding their prefix "A1S_". The efflux proteins in red are those up-regulated under high $\mathrm{Zn}$, in blue by high $\mathrm{Cu}$ and those in purple were found to be transcriptionally responsive to both high $\mathrm{Zn}$ and $\mathrm{Cu}$ independently (A1S_2939 and A1S_0709) or the combination of high Zn and high Cu (A1S_2939 and A1S_3098). Under high Zn and high Zn + $\mathrm{Cu}$ conditions, A. baumannii becomes increasingly sensitive to superoxide stress $\left(\mathrm{O}_{2}^{-}\right.$in the red burst), but shows increased resistance to hydrogen peroxide (green cloud). Under high Cu conditions, A. baumannii shows increased susceptibility to hydrogen peroxide $\left(\mathrm{H}_{2} \mathrm{O}_{2}\right.$ in the red burst). Under high Zn conditions and high Zn + Cu conditions, Cu levels reduce to 74 and 62\%, respectively

decreased by comparison to cells treated with $\mathrm{Zn}$ alone. These findings provide a potential explanation for the observed growth perturbations, which indicated that $\mathrm{Zn}$ and $\mathrm{Cu}$ have synergistic antimicrobial properties against $A$. baumannii, a phenotype highly conserved across the species and genus. The synergistic toxicity of $\mathrm{Zn}$ and $\mathrm{Cu}$ has been studied in many different organisms, since these two metals are often both found at elevated concentrations in industrial waste as well in agricultural pesticides [23, 72, 73].

The molecular basis for the $\mathrm{Cu}$ depletion observed in $\mathrm{Zn}$-stressed cells could be due to a failure of the cells to acquire adequate amounts of $\mathrm{Cu}$. To date, specific $\mathrm{Cu}$ uptake systems have not been identified in the cytoplasmic membrane of $A$. baumannii. Cytoplasmic $\mathrm{Cu}$ accumulation may occur via polyspecific uptake system(s) that also recognise other cations such as $\mathrm{Zn}$. Therefore, one possible explanation for the observed impact of $\mathrm{Zn}$ stress on $\mathrm{Cu}$ accumulation could be due to $\mathrm{Zn}$ competing for $\mathrm{Cu}$ uptake and/or decreased transcription of these uptake systems in the presence of elevated $\mathrm{Zn}$. However, while this model could plausibly explain the phenotype observed in the presence of high $\mathrm{Zn}$, it is inconsistent with the impact on $\mathrm{Cu}$ accumulation that occurred when $A$. baumannii was exposed to equimolar concentrations of $\mathrm{Zn}$ and $\mathrm{Cu}$. Based on our transcriptional analyses, we propose that the molecular basis for $\mathrm{Zn}$-induced $\mathrm{Cu}$ depletion in $\mathrm{A}$. baumannii is due to the up-regulation of efflux systems that preferentially efflux $\mathrm{Cu}$, a phenomenon similar to that seen for the effect of cadmium stress on $\mathrm{Zn}$ levels in S. pneumoniae [71]. Here, by combining phenotypic data and genomic observations from multiple $A$. baumannii species we can propose roles and contributions of various transporters to the metal resistome of this organism.

Interestingly, three resistance mechanisms were found to respond specifically to $\mathrm{Cu}$, but not $\mathrm{Zn}$ (A1S_1217, A1S_2932 and A1S_2935). These genes were also upregulated in $\mathrm{A}$. baumannii under $\mathrm{Zn}+\mathrm{Cu}$ stress, despite the significant $\mathrm{Cu}$ depletion seen in these cells (Figs. 2 and 8 ). The genes encoding the periplasmic CopAB-type Cu-resistance mechanism (A1S_2936 - A1S_2935) are divergently transcribed from a two-component regulatory system (A1S_2937 - A1S_2938), which typically sense their activating ligands in the periplasmic space. Indeed, A1S_2935 (copB) was the only $\mathrm{Cu}$-resistance gene expressed at the same level in $\mathrm{Zn}+\mathrm{Cu}$ stressed cells as that seen in $\mathrm{Cu}$-stressed cells only, which could indicate that $\mathrm{Cu}$ is accumulated at similar levels in the periplasm under $\mathrm{Cu}$ and $\mathrm{Zn}+\mathrm{Cu}$ stress. Consistent with these observation, studies from $E$. coli have shown that periplasmic $\mathrm{Cu}$ levels affect transcription of transporters responsible for exporting $\mathrm{Cu}$ from the cytosol to the periplasm in a complex regulatory hierarchy that includes both cytosolic (CueR and CopR) and periplasmic (CpxAR, CusRS, and YedWV) $\mathrm{Cu}$-sensing regulators [74-76]. 
Notably, despite observing a growth delay in the $\mathrm{Zn}$ and $\mathrm{Zn}+\mathrm{Cu}$ stressed cultures at mid-log-phase, their logarithmic growth rate remains unaffected (Fig. 1). This indicates that once the cells have adjusted to a high $\mathrm{Zn}$ environment during the lag-phase, their subsequent overall fitness is similar to that of untreated cells. In line with these findings, cells pre-treated with $\mathrm{Zn}$ overnight no longer exhibit a growth delay upon subsequent $\mathrm{Zn}$ stress (data not shown), similar to that observed by Williams et al. in the case of $\mathrm{Cu}$ stress [58]. Thus, $\mathrm{Cu}$ depletion does not appear to have major effects on the $A$. baumannii growth rate and may simply be a $\mathrm{Zn}$ stress adaptation strategy instead of an undesired consequence.

As seen in many other bacteria, metal ions play a key role in $A$. baumannii resistance to reactive oxygen species. Our examination of $A$. baumannii tolerance to $\mathrm{H}_{2} \mathrm{O}_{2}$ showed that cellular $\mathrm{Cu}$ levels play a key role in susceptibility to $\mathrm{H}_{2} \mathrm{O}_{2}$ toxicity. Conversely, high $\mathrm{Zn}$ levels are detrimental when $A$. baumannii encounters superoxide. Although not previously characterized, the A. baumannii genome features a gene encoding $\mathrm{Cu}-$ $\mathrm{Zn}$-SOD. In homologous enzymes, the $\mathrm{Cu}$ co-factor is essential for reaction efficiency, with $\mathrm{Zn}$ fulfilling structural roles. Hence, under $\mathrm{Zn}$ stress, i.e. $\mathrm{Cu}$ limitation, this enzyme may fail to aid in the detoxification of superoxide, resulting in oxidative stress. However, due to the similar effect of $\mathrm{Cu}$ stress on SOD activity and expression of the $\mathrm{Cu}-\mathrm{Zn}-\mathrm{SOD}$, the relative roles of the two A. baumannii SODs under metal stress require further examination. The significance of $\mathrm{Cu}$ and $\mathrm{Zn}$ as enzymatic co-factors was also suggested through examination of the bacterial membrane under $\mathrm{Zn}+\mathrm{Cu}$ stress. Production of the 18:1n-9 fatty acid requires a $\mathrm{Cu} / \mathrm{Fe}$-dependent delta-9 desaturase enzyme. This may explain the decreased abundance of this fatty acid in the $A$. baumannii membrane under $\mathrm{Cu}$-depleted conditions and the reduced tolerance to arachidonic acid.

Within macrophages, $\mathrm{Zn}, \mathrm{Cu}, \mathrm{H}_{2} \mathrm{O}_{2}, \mathrm{O}_{2}^{--}$and arachidonic acid have all been shown to be involved in killing pathogens, but whether a combination of these agents are employed simultaneously remains largely unknown and may be bacterium specific. Our analyses revealed that $\mathrm{Cu}$ enhances the ability of macrophages to kill $A$. baumannii and that $\mathrm{Zn}$ inhibits this action, thereby fitting the hypothesis that $\mathrm{H}_{2} \mathrm{O}_{2}$ plays an important role in macrophage-mediated killing of the pathogen. Interestingly, macrophages supplemented with $\mathrm{Zn}+\mathrm{Cu}$ displayed killing activity similar to that seen for untreated cells. This may be a result of $\mathrm{Zn}$ and $\mathrm{Cu}$ not being redirected to the same location as the phagocytosed bacteria within the macrophage, i.e. the results represent the average of $\mathrm{Zn}$ - or $\mathrm{Cu}$-treated macrophages, similar to that seen for Salmonella [32]. Alternatively, the combined effects of improved $\mathrm{H}_{2} \mathrm{O}_{2}$ tolerance, increased arachidonic acid sensitivity, and the general growth delay under $\mathrm{Zn}+\mathrm{Cu}$ stress may, overall, not reveal any significant differences.

\section{Conclusions}

Collectively, this work reveals the resistance strategies utilised by $A$. baumannii to survive metal ion stress, allowing it to thrive in diverse environments. However, our work also reveals a potential Achilles' heel, in which cellular $\mathrm{Cu}$ levels can be depleted by $\mathrm{Zn}$ stress and that this phenotype can be exacerbated by further supplementation with $\mathrm{Cu}$. This weakness could be exploited in the development of novel antimicrobial strategies to target $A$. baumannii in efforts to reduce the disease burden of this pathogen.

\section{Additional files}

Additional file 1: Graphs of the effect of stress on A. baumannii growth. Growth as determined by measuring the optical density at $600 \mathrm{~nm}$ $\left(\mathrm{OD}_{600}\right)$ of A. baumannii strain ATCC 17978 (400 $\mu \mathrm{M} Z \mathrm{Zn}, 400 \mu \mathrm{M}$ Cu or $400 \mu \mathrm{M} Z n+400 \mu \mathrm{M} C \mathrm{C})$ under stress induced by (A) $40 \mu \mathrm{M}$ paraquat $\left(\mathrm{O}_{2}^{-}\right)$, (B) $160 \mu \mathrm{M}$ hydrogen peroxide $\left(\mathrm{H}_{2} \mathrm{O}_{2}\right)$, or $(\mathrm{C}) 128 \mu \mathrm{M}$ arachidonic acid $(n \geq 3)$. (TIFF $470 \mathrm{~kb}$ )

Additional file 2: Table of oligonucleotides used in this study. (DOCX $75 \mathrm{~kb}$ ) Additional file 3: Table of the quantitative analysis of the $A$. baumannii transition metals under zinc and/or copper stress. (DOCX 42 kb)

Additional file 4: Analysis of Zn-Cu-SOD protein sequence. Identification of the Salmonella enterica and Escherichia coli Zn-CuSOD sequences by SignalP shows that the A. baumannii Zn-Cu-SOD lacks the signal sequence required for translocation to the cell's periplasm. (TIF $6360 \mathrm{~kb}$ )

\section{Acknowledgements}

Not applicable.

\section{Funding}

This work was supported by the National Health and Medical Research Council (Australia) through Project Grant 1060895 to ITP and KAH, Project Grant 1080784 to CAM and Program Grant 1071659 to JCP. BAE and CAM are supported by Channel 7 Children's Research Foundation Grant 161203, and KAH and LDHE by a Macquarie University Research Development Grant 9201401563. The work was also funded by the Australian Research Council Discovery Project Grants DP120101432 to JCP, and DP170102102 and DP150101856 to JCP and CAM. JCP is a NHMRC Senior Principal Research Fellow.

\section{Availability of data and material}

The datasets used and/or analysed during the current study are available from the corresponding authors on reasonable request.

\section{Authors' contributions}

$B A E, K A H, V G P, J C P, I T P$ and CAM designed the study. BAE, KAH, VGP and LDHE performed the experiments. BAE, KAH, VGP, CAM, LDHE, JCP and ITP contributed to the drafting of the manuscript. All authors read and approved the final manuscript.

\section{Competing interests}

The authors declare that they have no competing interests

Consent for publication

Not applicable. 


\section{Ethics approval and consent to participate}

Not applicable.

\section{Author details}

'Department of Chemistry and Biomolecular Sciences, Macquarie University, Sydney, NSW, Australia. ${ }^{2}$ Research Centre for Infectious Diseases, School of Biological Sciences, University of Adelaide, Adelaide, SA, Australia.

Received: 5 January 2017 Accepted: 24 February 2017

Published online: 11 March 2017

\section{References}

1. Dijkshoorn L, Nemec A, Seifert H. An increasing threat in hospitals: multidrug-resistant Acinetobacter baumannii. Nat Rev Microbiol. 2007;5(12) 939-51.

2. Antunes LC, Visca P, Towner KJ. Acinetobacter baumannii: evolution of a global pathogen. Pathog Dis. 2014;71(3):292-301.

3. Farrugia DN, Elbourne LD, Hassan KA, Eijkelkamp BA, Tetu SG, Brown MH, Shah BS, Peleg AY, Mabbutt BC, Paulsen IT. The complete genome and phenome of a community-acquired Acinetobacter baumannii. PLoS One. 2013;8(3):e58628

4. Eijkelkamp BA, Stroeher UH, Hassan KA, Paulsen IT, Brown MH. Comparative analysis of surface-exposed virulence factors of Acinetobacter baumannii. BMC Genomics. 2014;15:1020.

5. Anstey NM, Currie BJ, Withnall KM. Community-acquired Acinetobacter pneumonia in the Northern Territory of Australia. Clin Infect Dis. 1992:14(1):83-91.

6. Chan AP, Sutton G, DePew J, Krishnakumar R, Choi Y, Huang XZ, Beck E, Harkins DM, Kim M, Lesho EP, et al. A novel method of consensus panchromosome assembly and large-scale comparative analysis reveal the highly flexible pan-genome of Acinetobacter baumannii. Genome Biol. 2015; 16:143

7. Cerqueira GM, Peleg AY. Insights into Acinetobacter baumannii pathogenicity. IUBMB Life. 2011;63(12):1055-60.

8. Cerqueira GM, Kostoulias X, Khoo C, Aibinu I, Qu Y, Traven A, Peleg AY. A global virulence regulator in Acinetobacter baumannii and its control of the phenylacetic acid catabolic pathway. J Infect Dis. 2014;210(1):46-55.

9. Eijkelkamp BA, Stroeher UH, Hassan KA, Elbourne LD, Paulsen IT, Brown MH. $\mathrm{H}-\mathrm{NS}$ plays a role in expression of Acinetobacter baumannii virulence features. Infect Immun. 2013:81(7):2574-83.

10. Eijkelkamp BA, Stroeher UH, Hassan KA, Papadimitrious MS, Paulsen IT, Brown MH. Adherence and motility characteristics of clinical Acinetobacter baumannii isolates. FEMS Microbiol Lett. 2011;323(1):44-51.

11. Gayoso CM, Mateos J, Mendez JA, Fernandez-Puente P, Rumbo C, Tomas M, Martinez de llarduya O, Bou G. Molecular mechanisms involved in the response to desiccation stress and persistence in Acinetobacter baumannii. J Proteome Res. 2014;13(2):460-76.

12. Hood Ml, Mortensen BL, Moore JL, Zhang Y, Kehl-Fie TE, Sugitani N, Chazin WJ, Caprioli RM, Skaar EP. Identification of an Acinetobacter baumannii zinc acquisition system that facilitates resistance to calprotectin-mediated zinc sequestration. PLoS Pathog. 2012;8(12):e1003068.

13. Mortensen BL, Rathi S, Chazin WJ, Skaar EP. Acinetobacter baumannii response to host-mediated zinc limitation requires the transcriptional regulator Zur. J Bacteriol. 2014;196(14):2616-26.

14. Eijkelkamp BA, Hassan KA, Paulsen IT, Brown MH. Investigation of the human pathogen Acinetobacter baumannii under iron limiting conditions. BMC Genomics. 2011:12:126.

15. Dorsey CW, Beglin MS, Actis LA. Detection and analysis of iron uptake components expressed by Acinetobacter baumannii clinical isolates. J Clin Microbiol. 2003;41(9):4188-93.

16. Gaddy JA, Arivett BA, McConnell MJ, Lopez-Rojas R, Pachon J, Actis LA. Role of acinetobactin-mediated iron acquisition functions in the interaction of Acinetobacter baumannii strain ATCC 19606T with human lung epithelial cells, Galleria mellonella caterpillars, and mice. Infect Immun. 2012;80(3): $1015-24$.

17. Nwugo CC, Gaddy JA, Zimbler DL, Actis LA. Deciphering the iron response in Acinetobacter baumannii: A proteomics approach. J Proteomics. 2011; 74(1):44-58.

18. Penwell WF, Arivett $B A$, Actis LA. The Acinetobacter baumannii entA gene located outside the acinetobactin cluster is critical for siderophore production, iron acquisition and virulence. PLoS One. 2012;7(5):e36493.
19. Zimbler DL, Penwell WF, Gaddy JA, Menke SM, Tomaras AP, Connerly PL, Actis LA. Iron acquisition functions expressed by the human pathogen Acinetobacter baumannii. Biometals. 2009;22(1):23-32

20. Smani Y, McConnell MJ, Pachon J. Role of fibronectin in the adhesion of Acinetobacter baumannii to host cells. PLoS One. 2012;7(4):e33073.

21. Xu FF, Imlay JA. Silver(I), mercury(II), cadmium(II), and zinc(II) target exposed enzymic iron-sulfur clusters when they toxify Escherichia coli. Appl Environ Microbiol. 2012;78(10):3614-21.

22. Macomber L, Imlay JA. The iron-sulfur clusters of dehydratases are primary intracellular targets of copper toxicity. Proc Natl Acad Sci U S A. 2009; 106(20):8344-9.

23. Bruins MR, Kapil S, Oehme FW. Microbial resistance to metals in the environment. Ecotoxicol Environ Saf. 2000:45(3):198-207.

24. Turner AG, Ong CL, Gillen CM, Davies MR, West NP, McEwan AG, Walker MJ. Manganese homeostasis in group A Streptococcus is critical for resistance to oxidative stress and virulence. MBio. 2015;6(2):e00278-15

25. McDevitt CA, Ogunniyi AD, Valkov E, Lawrence MC, Kobe B, McEwan AG, Paton JC. A molecular mechanism for bacterial susceptibility to zinc. PLoS Pathog. 2011;7(11):e1002357.

26. Ong CL, Walker MJ, McEwan AG. Zinc disrupts central carbon metabolism and capsule biosynthesis in Streptococcus pyogenes. Sci Rep. 2015:5:10799.

27. Eijkelkamp BA, Morey JR, Ween MP, Ong CL, McEwan AG, Paton JC, McDevitt CA. Extracellular zinc competitively inhibits manganese uptake and compromises oxidative stress management in Streptococcus pneumoniae. PLoS One. 2014;9(2):e89427.

28. Eijkelkamp BA, McDevitt CA, Kitten T. Manganese uptake and streptococcal virulence. Biometals. 2015;28(3):491-508.

29. Chaturvedi KS, Henderson JP. Pathogenic adaptations to host-derived antibacterial copper. Front Cell Infect Microbiol. 2014;4:3.

30. Hodgkinson V, Petris MJ. Copper homeostasis at the host-pathogen interface. J Biol Chem. 2012;287(17):13549-55.

31. Vanhove AS, Rubio TP, Nguyen AN, Lemire A, Roche D, Nicod J, Vergnes A, Poirier AC, Disconzi E, Bachere E, et al. Copper homeostasis at the host vibrio interface: lessons from intracellular vibrio transcriptomics. Environ Microbiol. 2016;18(3):875-88.

32. Kapetanovic R, Bokil NJ, Achard ME, Ong CY, Peters KM, Stocks CJ, Phan MD Monteleone M, Schroder K, Irvine KM, et al. Salmonella employs multiple mechanisms to subvert the TLR-inducible zinc-mediated antimicrobial response of human macrophages. FASEB J. 2016;30(5):1901-12.

33. Achard ME, Stafford SL, Bokil NJ, Chartres J, Bernhardt PV, Schembri MA Sweet MJ, McEwan AG. Copper redistribution in murine macrophages in response to Salmonella infection. Biochem J. 2012;444(1):51-7.

34. Djoko KY, Ong CL, Walker MJ, McEwan AG. The role of copper and zinc toxicity in innate immune defense against bacterial pathogens. J Biol Chem. 2015:290(31):18954-61.

35. Besold AN, Culbertson EM, Culotta VC. The Yin and Yang of copper during infection. J Biol Inorg Chem. 2016;21(2):137-44.

36. Hantke K. Bacterial zinc transporters and regulators. Biometals. 2001;14(3-4): 239-49.

37. Nies DH. Efflux-mediated heavy metal resistance in prokaryotes. FEMS Microbiol Rev. 2003:27(2-3):313-39.

38. Drees SL, Beyer DF, Lenders-Lomscher C, Lubben M. Distinct functions of serial metal-binding domains in the Escherichia coli P1 B -ATPase CopA. Mol Microbiol. 2015;97(3):423-38.

39. Grass G, Rensing C. CueO is a multi-copper oxidase that confers copper tolerance in Escherichia coli. Biochem Biophys Res Commun. 2001;286(5): 902-8.

40. Cha JS, Cooksey DA. Copper resistance in Pseudomonas syringae mediated by periplasmic and outer membrane proteins. Proc Natl Acad Sci U S A 1991:88(20):8915-9.

41. Alvarez-Ortega C, Olivares J, Martinez JL. RND multidrug efflux pumps: what are they good for? Front Microbiol. 2013:4:7.

42. Yamaguchi A, Nakashima R, Sakurai K. Structural basis of RND-type multidrug exporters. Front Microbiol. 2015:6:327.

43. Fung DK, Lau WY, Chan WT, Yan A. Copper efflux is induced during anaerobic amino acid limitation in Escherichia coli to protect iron-sulfur cluster enzymes and biogenesis. J Bacteriol. 2013;195(20):4556-68.

44. Lu M, Fu D. Structure of the zinc transporter YiiP. Science. 2007:317(5845): 1746-8.

45. Worlock AJ, Smith RL. ZntB is a novel Zn2+ transporter in Salmonella enterica serovar Typhimurium. J Bacteriol. 2002;184(16):4369-73. 
46. Wan Q, Ahmad MF, Fairman J, Gorzelle B, de la Fuente M, Dealwis C, Maguire ME. X-ray crystallography and isothermal titration calorimetry studies of the Salmonella zinc transporter ZntB. Structure. 2011;19(5):700-10.

47. Pederick VG, Eijkelkamp BA, Begg SL, Ween MP, McAllister LJ, Paton JC, McDevitt CA. ZnuA and zinc homeostasis in Pseudomonas aeruginosa. Sci Rep. 2015:5:13139.

48. Eijkelkamp BA, Pederick VG, Plumptre CD, Harvey RM, Hughes CE, Paton JC, McDevitt CA. The first histidine triad motif of PhtD is critical for zinc homeostasis in Streptococcus pneumoniae. Infect Immun. 2016;84(2):407-15.

49. Plumptre CD, Eijkelkamp BA, Morey JR, Behr F, Counago RM, Ogunniyi AD, Kobe B, O'Mara ML, Paton JC, McDevitt CA. AdcA and AdcAll employ distinct zinc acquisition mechanisms and contribute additively to zinc homeostasis in Streptococcus pneumoniae. Mol Microbiol. 2014;91(4):834-51.

50. Plumptre CD, Hughes CE, Harvey RM, Eijkelkamp BA, McDevitt CA, Paton JC. Overlapping functionality of the Pht proteins in zinc homeostasis of Streptococcus pneumoniae. Infect Immun. 2014;82(10):4315-24.

51. Altschul SF, Gish W, Miller W, Myers EW, Lipman DJ. Basic local alignment search tool. J Mol Biol. 1990;215(3):403-10.

52. Lechner M, Findeiss S, Steiner L, Marz M, Stadler PF, Prohaska SJ. Proteinortho: detection of (co-)orthologs in large-scale analysis. BMC Bioinformatics. 2011;12:124.

53. Elbourne LD, Tetu SG, Hassan KA, Paulsen IT. TransportDB 2.0: a database for exploring membrane transporters in sequenced genomes from all domains of life. Nucleic Acids Res. 2017;45(D1):D320-d324.

54. Sullivan MJ, Petty NK, Beatson SA. Easyfig: a genome comparison visualizer. Bioinformatics. 2011;27(7):1009-10.

55. Hassan KA, Jackson SM, Penesyan A, Patching SG, Tetu SG, Eijkelkamp BA, Brown MH, Henderson PJ, Paulsen IT. Transcriptomic and biochemical analyses identify a family of chlorhexidine efflux proteins. Proc Natl Acad Sci U S A. 2013;110(50):20254-9.

56. Giles SK, Stroeher UH, Eijkelkamp BA, Brown MH. Identification of genes essential for pellicle formation in Acinetobacter baumannii. BMC Microbiol. 2015;15:116.

57. Pederick VG, Eijkelkamp BA, Ween MP, Begg SL, Paton JC, McDevitt CA. Acquisition and role of molybdate in Pseudomonas aeruginosa. Appl Environ Microbiol. 2014;80(21):6843-52.

58. Williams CL, Neu HM, Gilbreath JJ, Michel SL, Zurawski DV, Merrell DS. Copper resistance of the emerging pathogen Acinetobacter baumannii. Appl Environ Microbiol. 2016;82(20):6174-88.

59. Mumm K, Ainsaar K, Kasvandik S, Tenson T, Horak R. Responses of Pseudomonas putida to zinc excess determined at the proteome level: Pathways dependent and independent of CoIRS. J Proteome Res. 2016; 15(12):4349-68.

60. Teitzel GM, Geddie A, De Long SK, Kirisits MJ, Whiteley M, Parsek MR. Survival and growth in the presence of elevated copper: transcriptional profiling of copper-stressed Pseudomonas aeruginosa. J Bacteriol. 2006; 188(20):7242-56

61. Latorre M, Low M, Garate E, Reyes-Jara A, Murray BE, Cambiazo V, Gonzalez M. Interplay between copper and zinc homeostasis through the transcriptional regulator Zur in Enterococcus faecalis. Metallomics. 2015;7(7):1137-45.

62. Adams MD, Goglin K, Molyneaux N, Hujer KM, Lavender H, Jamison JJ, MacDonald IJ, Martin KM, Russo T, Campagnari AA, et al. Comparative genome sequence analysis of multidrug-resistant Acinetobacter baumannii. J Bacteriol. 2008;190(24):8053-64

63. Ou HY, Kuang SN, He X, Molgora BM, Ewing PJ, Deng Z, Osby M, Chen W, $\mathrm{Xu} \mathrm{HH}$. Complete genome sequence of hypervirulent and outbreakassociated Acinetobacter baumannii strain LAC-4: epidemiology, resistance genetic determinants and potential virulence factors. Sci Rep. 2015:5:8643.

64. Farrugia DN, Elbourne LD, Mabbutt BC, Paulsen IT. A novel family of integrases associated with prophages and genomic islands integrated within the tRNA-dihydrouridine synthase A (dusA) gene. Nucleic Acids Res. 2015;43(9):4547-57.

65. Imlay JA. Pathways of oxidative damage. Annu Rev Microbiol. 2003;57:395-418.

66. Heindorf M, Kadari M, Heider C, Skiebe E, Wilharm G. Impact of Acinetobacter baumannii superoxide dismutase on motility, virulence, oxidative stress resistance and susceptibility to antibiotics. PLoS One. 2014; 9(7):e101033.

67. Sansone A, Watson PR, Wallis TS, Langford PR, Kroll JS. The role of two periplasmic copper- and zinc-cofactored superoxide dismutases in the virulence of Salmonella choleraesuis. Microbiology. 2002;148(Pt 3):719-26.
68. Gort AS, Ferber DM, Imlay JA. The regulation and role of the periplasmic copper, zinc superoxide dismutase of Escherichia coli. Mol Microbiol. 1999; 32(1):179-91.

69. Sakamoto T, Murata N. Regulation of the desaturation of fatty acids and its role in tolerance to cold and salt stress. Curr Opin Microbiol. 2002;5(2):208-10.

70. Das UN. Antibiotic-like action of essential fatty acids. Can Med Assoc J. 1985; 132(12):1350.

71. Begg SL, Eijkelkamp BA, Luo Z, Counago RM, Morey JR, Maher MJ, Ong CL, McEwan AG, Kobe B, O'Mara ML, et al. Dysregulation of transition metal ion homeostasis is the molecular basis for cadmium toxicity in Streptococcus pneumoniae. Nat Commun. 2015:6:6418.

72. Mebane CA, Dillon FS, Hennessy DP. Acute toxicity of cadmium, lead, zinc, and their mixtures to stream-resident fish and invertebrates. Environ Toxicol Chem. 2012;31(6):1334-48.

73. Sharma SS, Schat H, Vooijs R, Van Heerwaarden LM. Combination toxicology of copper, zinc, and cadmium in binary mixtures: Concentration-dependent antagonistic, nonadditive, and synergistic effects on root growth in Silene vulgaris. Environ Toxicol Chem. 1999;18(2):348-55.

74. Batchelor E, Walthers D, Kenney LJ, Goulian M. The Escherichia coli CpxACpxR envelope stress response system regulates expression of the porins ompF and ompC. J Bacteriol. 2005;187(16):5723-31.

75. Yamamoto K, Ishihama A. Characterization of copper-inducible promoters regulated by CpxA/CpxR in Escherichia coli. Biosci Biotechnol Biochem. 2006; 70(7):1688-95.

76. Yamamoto K, Ishihama A. Transcriptional response of Escherichia coli to external copper. Mol Microbiol. 2005;56(1):215-27.

\section{Submit your next manuscript to BioMed Central and we will help you at every step:}

- We accept pre-submission inquiries

- Our selector tool helps you to find the most relevant journal

- We provide round the clock customer support

- Convenient online submission

- Thorough peer review

- Inclusion in PubMed and all major indexing services

- Maximum visibility for your research

Submit your manuscript at www.biomedcentral.com/submit 